\title{
Regulation of Synaptic Amyloid- $\beta$ Generation through BACE1 Retrograde Transport in a Mouse Model of Alzheimer's Disease
}

\author{
Xuan Ye, ${ }_{1}^{1}$ TTuancheng Feng, ${ }^{1}$ Prasad Tammineni, ${ }^{1}$ Qing Chang, ${ }^{2}$ Yu Young Jeong, ${ }^{1}$ @David J. Margolis, ${ }^{1}$ \\ Huaibin Cai, ${ }^{3}$ Alexander Kusnecov, ${ }^{2}$ and $\mathbb{Q}^{-}$ian Cai ${ }^{1}$ \\ Departments of ${ }^{1}$ Cell Biology and Neuroscience and ${ }^{2}$ Psychology, Rutgers University, Piscataway, New Jersey 08854 and ${ }^{3}$ Laboratory of Neurogenetics, \\ National Institute on Aging, Bethesda, Maryland 20892
}

Amyloid- $\beta(\mathrm{A} \beta$ ) peptides play a key role in synaptic damage and memory deficits in the early pathogenesis of Alzheimer's disease (AD). Abnormal accumulation of $A \beta$ at nerve terminals leads to synaptic pathology and ultimately to neurodegeneration. $\beta$-site amyloid precursor protein (APP) cleaving enzyme 1 (BACE1) is the major neuronal $\beta$-secretase for $\mathrm{A} \beta$ generation. However, the mechanisms regulating BACE1 distribution in axons and $\beta$ cleavage of APP at synapses remain largely unknown. Here, we reveal that dynein-Snapin-mediated retrograde transport regulates BACE1 trafficking in axons and APP processing at presynaptic terminals. BACE1 is predominantly accumulated within late endosomes at the synapses of AD-related mutant human APP (hAPP) transgenic ( $\mathrm{Tg}$ ) mice and patient brains. Defective retrograde transport by genetic ablation of snapin in mice recapitulates late endocytic retention of BACE1 and increased APP processing at presynaptic sites. Conversely, overexpressing Snapin facilitates BACE1 trafficking and reduces synaptic BACE1 accumulation by enhancing the removal of BACE1 from distal $\mathrm{AD}$ axons and presynaptic terminals. Moreover, elevated Snapin expression via stereotactic hippocampal injections of adeno-associated virus particles in mutant hAPP Tg mouse brains decreases synaptic $\mathrm{A} \beta$ levels and ameliorates synapse loss, thus rescuing cognitive impairments associated with hAPP mice. Altogether, our study provides new mechanistic insights into the complex regulation of BACE1 trafficking and presynaptic localization through Snapin-mediated dynein-driven retrograde axonal transport, thereby suggesting a potential approach of modulating $\mathrm{A} \beta$ levels and attenuating synaptic deficits in $\mathrm{AD}$.

Key words: APP processing; axonal transport; BACE1 trafficking; late endosome; Snapin; synapse

Significance Statement

$\beta$-Site amyloid precursor protein (APP) cleaving enzyme 1 (BACE1) trafficking and synaptic localization significantly influence its $\beta$ secretase activity and amyloid- $\beta(\mathrm{A} \beta)$ production. In AD brains, BACE1 is accumulated within dystrophic neurites, which is thought to augment $A \beta$-induced synaptotoxicity by $\mathrm{A} \beta$ overproduction. However, it remains largely unknown whether axonal transport regulates synaptic APP processing. Here, we demonstrate that Snapin-mediated retrograde transport plays a critical role in removing BACE1 from presynaptic terminals toward the soma, thus reducing synaptic A $\beta$ production. Adeno-associated virus-mediated Snapin overexpression in the hippocampus of mutant hAPP mice significantly decreases synaptic A $\beta$ levels, attenuates synapse loss, and thus rescues cognitive deficits. Our study uncovers a new pathway that controls synaptic APP processing by enhancing axonal BACE1 trafficking, thereby advancing our fundamental knowledge critical for ameliorating A $\beta$-linked synaptic pathology.

\section{Introduction}

Accumulation of amyloid- $\beta(\mathrm{A} \beta)$ deposits as senile plaques is a pathological hallmark of Alzheimer's disease (AD). Presynaptic

\footnotetext{
Received Sept. 11, 2016; revised Jan. 2, 2017; accepted Jan. 9, 2017.

Author contributions:X.Y., T.F., P.T., A.K., and Q. Cai designed research; X.Y., T.F., P.T., Q. Chang, Y.Y.J., and Q. Cai performed research; D.J.M. and H.C. contributed unpublished reagents/analytic tools; X.Y., T.F., P.T., Q. Chang, Y.Y.J., A.K., and Q. Cai analyzed data; A.K. and Q. Cai wrote the paper.

This work was supported by National Institutes of Health Grants R00AG033658 and R01NS089737 (Q. (ai), MH104800 and MH108994 (A.K.), and R01NS094450 (D.M.); Alzheimer's Association Grant NIRG-14-321833 (Q. Cai); and the Charles and Johanna Busch Biomedical Award (Q. Cai). We thankZ.-H. Sheng at the NINDS for snapin mutant mouse lines and important reagents; S. Cheng at the NINDS EM facility, V. Starovoytov at the Rutgers
}

terminals have been implicated as a major site for $\mathrm{A} \beta$ generation, thus contributing to synaptic deficits (Coleman and Yao, 2003; Mucke and Selkoe, 2012; Buggia-Prévot and Thinakaran, 2015). A growing body of evidence indicates that $\mathrm{A} \beta$ accumulation leads

Department of Cell Biology and Neuroscience EM facility, and R. Patel at the Robert Wood Johnson Medical Schoo Department of Pathology and Laboratory Medicine EM facility for technical help; C. Agrawal and S. McEwan for editing; and E Gavin, J. Lam, R. Pillai, A. Yao, D. Aikal, J. Sheu, and other members in Q. Cai lab for their research assistance. We thank the Harvard Tissue Resource Center (supported by NIH Grant HHSN-271-2013-00030C) and the Human Brain and Spinal Fluid Resource Center at the University of California, Los Angeles, for providing the postmortem brain specimens from AD patients and age-matched control subjects. 
to synaptic dysfunction and neurodegeneration (Coleman and Yao, 2003; Mucke and Selkoe, 2012; Buggia-Prévot and Thinakaran, 2015). A $\beta$ peptide is derived from sequential proteolysis of amyloid precursor protein (APP) by $\beta$ and $\gamma$ secretases, with $\beta$ secretase considered the initial and rate-limiting enzyme during this process (Sinha et al., 1999; Vassar et al., 1999, 2009; Yan et al., 1999; Cai et al., 2001). The major neuronal $\beta$-secretase responsible for $\mathrm{A} \beta$ generation is $\beta$-site APP-cleaving enzyme 1 (BACE1; Sinha et al., 1999; Vassar et al., 1999; Yan et al., 1999; Cai et al., 2001). The levels of BACE1 increase with age (Fukumoto et al., 2004) and are elevated in $\mathrm{AD}$ patient brains (Yang et al., 2003), thereby making BACE1 a prime target for therapeutic intervention. Indeed, in $\mathrm{AD}$ mouse models and human patient brains, BACE1 is abnormally retained in swollen presynaptic dystrophic neurites surrounding amyloid plaques in the cortex and hippocampus (Zhang et al., 2009; Kandalepas et al., 2013), suggesting increased $\beta$ cleavage of APP in these regions. Although BACE1 has been shown to undergo dynamic transport in neurons (Buggia-Prévot and Thinakaran, 2015), it is not known whether defects in this transport route contribute to BACE1 accumulation within $\mathrm{AD}$ neurites, thus enhancing $A \beta$ generation at synaptic terminals.

We reported previously that Snapin, a dynein motor adaptor, mediates retrograde transport of late endosomes (LEs) in neurons (Cai et al., 2010). Our recent study showed defects in the dyneindriven retrograde transport of BACE1 in AD neurons (Ye and Cai, 2014). These findings raise a fundamental question: does axonal transport of BACE1 play a key role in regulating its trafficking and presynaptic localization, thus limiting APP processing at axonal terminals? Many studies focused on BACE trafficking in nonneuronal cells (Sannerud et al., 2011; Bhalla et al., 2012) or neuron-derived cell lines (Tesco et al., 2007; Kang et al., 2012). However, it remains unknown whether axonal transport regulates synaptic BACE1 trafficking. It is critical and urgent to investigate how altered axonal transport of BACE1 impacts its trafficking and thus APP processing at presynaptic terminals in an $\mathrm{AD}$-related neuronal system. Snapindeficient mice serve as a unique genetic model to address this issue. Here, using genetic mouse models and time-lapse imaging analyses in live neurons combined with gene rescue experiments in both in vitro and in vivo systems, we reveal that Snapin-mediated retrograde transport regulates BACE1 trafficking and $\beta$ cleavage of APP at presynaptic terminals. Snapin overexpression in the hippocampus of mutant hAPP J20 transgenic (Tg) mouse brains significantly decreased synaptic $A \beta$ levels, ameliorated synapse loss, and rescued behavioral deficits in nonspatial and spatial learning in novel object recognition and a water maze (MWM); and in contextual fear conditioning, all of these behavioral deficits are associated with mutant hAPP Tg mice. Therefore, our study uncovers a novel cellular pathway that effectively regulates axonal BACE1 trafficking and synaptic APP processing through Snapin-mediated retrograde transport, thus advancing our knowledge that may be critical for limiting $\mathrm{A} \beta$ production at nerve terminals.

\section{Materials and Methods \\ Materials}

H. Cai (National Institute on Aging, NIH, Bethesda, MD) kindly provided the anti-BACE1 antibody. pBACE1-GFP, monomeric red fluorescent protein (mRFP)-Rab7, and pmRFP-synaptophysin (SYP) were from W. Song (University of British Columbia, Vancouver, Canada), and Z.-H. Sheng (National Institute of Neurologic Disorders and Stroke, NIH, Bethesda,

The authors declare no competing financial interests.

Correspondence should be addressed to Qian Cai at the above address. E-mail: cai@biology.rutgers.edu. DOI:10.1523/JNEUROSCI.2851-16.2017

Copyright $\odot 2017$ the authors $\quad 0270-6474 / 17 / 372640-17 \$ 15.00 / 0$
Table 1. Demographic details of postmortem brain specimens from patients with $A D$ and subjects without $A D$

\begin{tabular}{llcl}
\hline Case type & $\begin{array}{l}\text { Age (years)/ } \\
\text { sex }\end{array}$ & $\begin{array}{l}\text { Postmortem } \\
\text { interval }(\mathrm{h})\end{array}$ & $\begin{array}{l}\text { Braak stage of } \\
\text { AD brains }\end{array}$ \\
\hline Control & $75 / \mathrm{F}$ & 20.1 & 0 \\
Control & $87 / \mathrm{M}$ & 9.3 & 0 \\
Control & $47 / \mathrm{M}$ & 12.5 & 0 \\
Control & $66 / \mathrm{M}$ & 22.5 & 0 \\
Control & $73 / \mathrm{M}$ & 20.9 & 0 \\
AD & $72 / \mathrm{M}$ & 21.8 & $\mathrm{II}$ \\
AD & $86 / \mathrm{M}$ & 9.00 & $\mathrm{III}$ \\
AD & $86 / \mathrm{M}$ & 17.4 & $\mathrm{II}$ \\
AD & $69 / \mathrm{F}$ & 15.4 & $\mathrm{~V}$ \\
AD & $86 / \mathrm{F}$ & 7.08 & $\mathrm{VI}$ \\
\hline
\end{tabular}

M, Male; F, female.

MD), respectively. The constructs encoding Snapin, yellow fluorescent protein (YFP)-Rab7, and AAV9-mCherry-Snapin and AAV9-mCherry were kindly provided by Z.-H. Sheng as described previously (Cai et al., 2010; Zhou et al., 2012; Xie et al., 2015). The purified polyclonal antibody against mouse N-terminal Snapin was described previously (Tian et al., 2005). Snapin constructs and antibody were obtained from Z.-H. Sheng. Sources of other antibodies and reagents are as follows: polyclonal anti-EEA1 (Santa Cruz Biotechnology, catalog \#sc-6416, RRID:AB_640035) and antisynaptophysin (Santa Cruz Biotechnology, catalog \#sc-9116, RRID: AB_2199007) antibodies; monoclonal anti-dynein intermediate chain (DIC; Millipore, catalog \#MAB1618, RRID:AB_2246059), anti-synaptophysin (Millipore, catalog \#MAB5258, RRID:AB_11214133), anti-GAPDH (Millipore, catalog \#CB1001, RRID:AB_2107426) antibodies, and polyclonal antiAPP c-terminal (Millipore, catalog \#AB5352, RRID:AB_91793) antibody; monoclonal anti-mCherry (Clontech, catalog \#632543, RRID:AB_2307319) antibody; monoclonal anti-Rab7 (Sigma, catalog \#R8779, RRID: AB_609910) and polyclonal SNAP-25 (Sigma, catalog \#S9684, RRID: AB_261576) antibodies; monoclonal anti- $\beta$ Amyloid (6E10) antibody (Covance, catalog \#SIG-39320, RRID:AB_2564653); monoclonal anti-p115 (BD Biosciences, catalog \#612261, RRID:AB_399578) and anti-MAP2 (BD Biosciences, catalog \#556320, RRID:AB_396359) antibodies; monoclonal anti-PSD95 antibody (Millipore, catalog \#05-494, discontinued); and polyclonal anti-oligomer A11 (Invitrogen, catalog \#AHB0052, RRID: AB_2536236) and Alexa fluor 488-conjugated (Invitrogen, catalog \#A11070, RRID:AB_142134; catalog \#A11017, AB_143160) and 546-conjugated (Invitrogen, catalog \#A11071, RRID:AB_2534115; catalog \#A11018, RRID: AB_2534085) secondary antibodies. The monoclonal anti-cationindependent mannose 6-phosphate receptor (CI-MPR; catalog \#86f7, RRID:AB_528348) antibody was developed by J. T. August and was obtained from the Developmental Studies Hybridoma Bank.

Mice

The snapin flox mice were provided by Z.-H. Sheng. CaMKII $\alpha$-tTA (RRID:IMSR_JAX:003010) and tet-APPswe/ind (RRID:MMRRC_034834JAX) mice were obtained from H. Cai. hAPP mice (C57BL/6J) from line J20 (https://www.jax.org/strain/006293; Mucke et al., 2000) and Thy1Cre Tg (RRID:IMSR_JAX:006143) mice (Campsall et al., 2002) were purchased from The Jackson Laboratory. Animal care and use in this study was performed in accordance with Rutgers University Institutional Animal Care and Use Committee standards. The animal facilities at Rutgers University are fully Association for Assessment and Accreditation of Laboratory Animal Care accredited.

\section{Human brain specimens}

Postmortem brain specimens from AD patients and age-matched control subjects were obtained from the Harvard Tissue Resource Center and the Human Brain and Spinal Fluid Resource Center at the University of California, Los Angeles (Table 1). Specimens were from patients diagnosed with AD according to Braak criteria (Braak and Braak, 1991). The specimens were from the frontal cortex and were quick-frozen (BA9). Five control subjects and five patient brains at different Braak stages with postmortem interval $7.08-22.5 \mathrm{~h}$ were used for synaptosomal fraction purification. 


\section{Immunoisolation of late endocytic organelles}

Brain tissues from WT or snapin conditional knock-out (cKO) mice were homogenized in the buffer (10 mM HEPES, pH 7.4, 1 mM EDTA, $0.25 \mathrm{M}$ sucrose, and protease inhibitors) and centrifuged at $800 \times g$ for $10 \mathrm{~min}$, and the supernatant was collected. The pellet was resuspended in the homogenization buffer using a glass rod with three to four gentle strokes of the pestle of the $30 \mathrm{ml}$ Dounce homogenizer and recentrifuged at $800 \times g$ for $10 \mathrm{~min}$. The combined first and second supernatants were centrifuged at $3500 \times g$ for $10 \mathrm{~min}$ and then collected for high-speed centrifugation at $20,000 \times g$ for $10 \mathrm{~min}$. The pellet was resuspended in the homogenization buffer using a glass rod with three to four gentle strokes of the pestle of the $30 \mathrm{ml}$ Dounce homogenizer and recentrifuged at $20,000 \times g$ for $10 \mathrm{~min}$. The pellet was then resuspended in the homogenization buffer and subjected to immunoisolation with tosylated linker-coated superparamagnetic beads (Dynabeads M-450 Subcellular; Invitrogen) as described in previous studies (Cai et al., 2010; Zhou et al., 2012; Ye and Cai, 2014; Cheng et al., 2015). For all subsequent steps, beads were collected with a magnetic device (MPC; Invitrogen). After washing once for $5 \mathrm{~min}$ in $\mathrm{PBS}, \mathrm{pH} 7.4$, with $0.1 \% \mathrm{BSA}$ at $4^{\circ} \mathrm{C}$, the linker-coated beads $(1.4 \mathrm{mg})$ were incubated with $1 \mu \mathrm{g}$ anti-Rab7 $\mathrm{mAb}$ or control mouse IgG overnight at $4^{\circ} \mathrm{C}$ on a rotator. After incubation, the beads were washed four times ( 5 min each) in PBS, pH 7.4, with $0.1 \%$ $\mathrm{BSA}$ at $4^{\circ} \mathrm{C}$, and then resuspended in an incubation buffer containing PBS, pH 7.4, 2 mm EDTA, and 5\% fetal bovine serum. Approximately 400 $\mu \mathrm{g}$ of light membrane fraction from WT or snapin cKO mouse brains was mixed with incubation buffer containing beads (final reaction volume 1 $\mathrm{ml}$ ) and incubated for $4 \mathrm{~h}$ at $4^{\circ} \mathrm{C}$ on a rotator. After incubation, the beads were collected with a magnetic device and washed five times with the incubation buffer and three times with PBS for $10 \mathrm{~min}$ each and then resolved by $4-12 \%$ Bis-Tris PAGE for sequential Western blots on the same membranes after stripping between each application of the antibody. For semiquantitative analysis, protein bands detected by ECL were scanned into Adobe Photoshop CS6 and analyzed using NIH ImageJ (RRID:SCR_003070).

\section{Preparation of synapse-enriched fractions}

Synaptosome (Syn) preparations from the brains of WT and mutant hAPP Tg (CaMKII $\alpha$-tTA $\times$ tet-APPswe/ind; Jankowsky et al., 2005) or snapin $\mathrm{CKO}$ mice or $\mathrm{AD}$ patients and age-matched controls were collected using Percoll gradient centrifugation as described previously (Leenders et al., 2004; DiGiovanni et al., 2012). Cortex tissues were homogenized in ice-cold sucrose buffer [10 mM HEPES, 2 mM EDTA, 0.64 $\mathrm{m}$ sucrose and protease inhibitors (Roche), $\mathrm{pH}$ 7.4]. Homogenates were centrifuged at $1000 \times g$ for $10 \mathrm{~min}$ and the supernatant was gathered and overlaid on Percoll gradients that had $2 \mathrm{ml}$ of $10 \%$ Percoll gradient layered over 15, 23, and 40\% Percoll gradients. The gradient was then separated by centrifugation for $5 \mathrm{~min}$ at $32,500 \times \mathrm{g}$. The synaptosomal fraction was collected from the interface of the 15 and $23 \%$ Percoll layers, and combined with $5 \mathrm{ml}$ the sucrose buffer. The mixture was then centrifuged at $15,000 \times g$ for $15 \mathrm{~min}$ and resuspended in the sucrose buffer. Protein quantification was performed by BCA assay (Pierce Chemical). Fifteen micrograms of protein from Syn and postnuclear supernatant (PNS) homogenates were resolved by $4-12 \%$ SDS-PAGE for sequential Western blots on the same membranes after stripping between each application of antibody.

\section{Measurement of $A \beta$ levels}

ELISA kits for mouse and human A $\beta 40$ (Invitrogen, catalog \#KMB3481 or KHB3481) were used to detect A $\beta 40$ levels in cortex in WT and snapin cKO mouse brains or in the hippocampi of mutant hAPP Tg mouse brains. In brief, cerebral cortices of WT or snapin cKO mice were homogenized in an $8 \times$ mass of cold guanidine buffer $(5 \mathrm{M}$ guanidine $\mathrm{HCl} / 50 \mathrm{~mm}$ Tris $\mathrm{HCl}, \mathrm{pH}$ 8.0) for ELISA. The homogenates were then diluted (at 1:10) with cold reaction buffer BSAT-DPBS (Dulbecco's PBS with 5\% BSA and $0.03 \%$ Tween- 20 plus $1 \times$ protease inhibitor cocktail). The supernatants from WT or snapin cKO mice collected after centrifugation $\left(16,000 \times g\right.$ for $20 \mathrm{~min}$ at $\left.4^{\circ} \mathrm{C}\right)$ or the Syn and PNS homogenates from control or snapin cKO mice or mutant hAPP Tg mice were subjected to ELISA analysis using the kit according to the manufacturer's instructions.

\section{Transfection of cultured cortical neurons}

Cortices were dissected from embryonic day 18 (E18)-E19 mouse embryos of mutant hAPP Tg mice or their WT littermates as described previously (Goslin et al., 1998; Cai et al., 2010, 2012; Ye and Cai, 2014). Cortical neurons were dissociated by papain (Worthington) and plated at a density of 200,000 cells $/ \mathrm{cm}^{2}$ on polyornithine- and fibronectincoated coverslips. Neurons were grown overnight in plating medium (5\% FBS, insulin, glutamate, G5, and $1 \times$ B27) supplemented with $100 \times$ $g$ L-glutamine in Neurobasal medium (Invitrogen). Starting at DIV 2, cultures were maintained in conditioned medium with half-feed changes of neuronal feed ( $1 \times$ B27 in Neurobasal medium) every $3 \mathrm{~d}$. Neurons were transfected with various constructs at DIV 5 using Lipofectamine 2000 (Invitrogen) followed by time-lapse imaging $4-5 \mathrm{~d}$ after transfection.

\section{Tissue preparation and immunohistochemistry}

Animals were anesthetized with $2.5 \%$ avertin $(0.35 \mathrm{ml}$ per mouse) and transcardially perfused with fixation buffer (4\% paraformaldehyde in PBS, pH 7.4). Brains were dissected out and postfixed in fixation buffer overnight and then placed in $30 \%$ sucrose at $4^{\circ} \mathrm{C}$. Ten-micrometer-thick coronal sections were collected consecutively to the level of the hippocampus and used to study colocalization of various markers. Antigen retrieval techniques were used for BACE1 labeling (50\% formamide and $50 \% 2 \times$ SSC at $65^{\circ} \mathrm{C}$ for $1 \mathrm{~h}$; Zhang et al., 2009). After incubation with blocking buffer ( $5 \%$ goat serum, $0.3 \%$ Triton X-100, 3\% BSA, $1 \%$ glycine in PBS) at room temperature (RT) for $1 \mathrm{~h}$, the sections were incubated with primary antibodies at $4^{\circ} \mathrm{C}$ overnight, followed by incubating with secondary fluorescence antibodies at 1:600 dilution at RT for $1 \mathrm{~h}$. After fluorescence immunolabeling, the sections were stained with DAPI and washed three times in PBS. The sections were then mounted with antifading medium (vector laboratories, H-5000) for imaging.

\section{Image acquisition and quantification}

Confocal images were obtained using an Olympus model FV1000-IX81 oil-immersion $60 \times$ objective on the sequential-acquisition setting. For fluorescent quantification, images were acquired using the same settings below saturation at a resolution of $1024 \times 1024$ pixels ( 8 bit). Eight to 10 sections were taken from top-to-bottom of the specimen and brightest point projections were made. Colocalization and morphometric measurements were performed using NIH ImageJ. Measured data were imported into Excel software for analysis. The thresholds in all images were set to similar levels. Data were obtained from at least three independent experiments, and the number of cells used for quantification is indicated in the figures. All statistical analyses were performed using Student's $t$ test and are presented as mean \pm SEM.

For live cell imaging, cells were transferred to Tyrode's solution containing the following (in mM): 10 HEPES, 10 glucose, $1.2 \mathrm{CaCl}_{2}, 1.2$ $\mathrm{MgCl}_{2}, 3 \mathrm{KCl}$, and $145 \mathrm{NaCl}, \mathrm{pH}$ 7.4. The temperature was maintained at $37^{\circ} \mathrm{C}$ with an air stream incubator. Cells were visualized with a $60 \times$ oil immersion lens (1.2 numerical aperture) on an Olympus FV1000 confocal microscope, using $488 \mathrm{~nm}$ excitation for GFP or YFP and $543 \mathrm{~nm}$ for mRFP or Rhodamine. Time-lapse sequences of $1024 \times 1024$ pixels ( 8 bit) were collected at $1-2 \mathrm{~s}$ intervals with $1 \%$ intensity of the argon laser to minimize laser-induced bleaching and damage to cells, and maximum pinhole opening. Time-lapse images were captured by a total of 100 frames. All recordings started $6 \mathrm{~min}$ after the coverslip was placed in the chamber. The stacks of representative images were imported into NIH ImageJ. A membranous organelle was considered stopped if it remained stationary for the entire recording period; a motile one was counted only if the displacement was at least $5 \mu \mathrm{m}$.

For analyzing the motility of BACE1 or Rab7 vesicles in live neurons, we selected axons for time-lapse imaging and measuring motility because axons, but not dendrites, have a uniform microtubule organization and polarity. Axonal processes were selected as we reported previously (Kang et al., 2008; Cai et al., 2010, 2012; Ye and Cai, 2014; Ye et al., 2015). Axons in live images were distinguished from dendrites based on known morphological characteristics: greater length, thin and uniform diameter, and sparse branching (Banker and Cowan, 1979). Only those that appeared to be single axons and separate from other processes in the field were chosen for recording axonal transport of BACE1 or Rab7. Regions where crossing or fasciculation occurred were excluded from analysis. 
Kymographs were used to trace axonal anterograde or retrograde movement of membranous organelles and to count stationary ones as described previously (Miller and Sheetz, 2004; Kang et al., 2008), with extra plugins for ImageJ. Briefly, we used the "Straighten" plugin to straighten curved axons and the "Grouped ZProjector" to $z$-axially project resliced time-lapsed images. The height of the kymographs represents recording time ( $100 \mathrm{~s}$ unless otherwise noted), while the width represents the length (in micrometers) of the axon imaged. Counts were averaged from 100 frames for each time-lapsed image to ensure accuracy of stationary and motile events. Measurements are presented as mean \pm SEM. Statistical analyses were performed using unpaired Student's $t$ tests.

Quantification of colocalization. A threshold intensity was preset for both fluorescent signals, which was determined with the thresholding function of NIH ImageJ. The colocalized pixels above the threshold intensity were automatically quantified and scored by ImageJ based on the fluorescence intensity profile expressed as colocalized mean intensity positive for both channels. Colocalization was presented as the colocalized mean intensity of BACE1 with MAP2, which were normalized to those from WT littermate controls. Data were obtained from at least three independent experiments, and the number of imaging brain slices used for quantification is indicated in the figures.

Quantification of the density of presynaptic terminals. Quantification of the density of presynaptic terminals was performed in the hippocampal dentate gyrus using SYP fluorescence as reported previously (Mucke et al., 2000; Nagahara et al., 2013). Sampled sections consisted of $320 \times 320$ $\mu \mathrm{m}$ images acquired with an Olympus confocal microscope at $2048 \times$ 2048 pixel resolution with a $40 \times$ objective lens. The number of pixels containing SYP immunoreactivity was measured per unit area above a minimum threshold intensity determined with the thresholding function of NIH ImageJ; histograms of pixel brightness reflecting a bimodal distribution of background peak (mode) and a smaller signal peak (SYP fluorescence), with a $1.5 \mathrm{SD}$ above background (mode), were generated. The area occupied by SYP-labeled presynaptic terminals was quantified and expressed as a percentage of the total image area as described previously (Mucke et al., 2000; Nagahara et al., 2013). To ensure objective assessments and reliability of results, brain sections from mice to be compared in any given experiment were blind coded and processed in parallel. Codes were broken after the analysis was complete.

Quantification of A11-labeled soluble A . A threshold intensity was preset and determined with the thresholding function of NIH ImageJ as described above. The mean intensity above the threshold intensity was automatically quantified and scored based on the A11 fluorescence intensity profile in the hippocampal regions. The results are expressed as the percentage difference from hAPP mice injected with adenoassociated virus (AAV) control. The number of imaging brain slices used for quantification is indicated in the figures.

Quantification of amyloid plaques. In this strain of APP transgenic mice, amyloid plaques were quantified in the hippocampus. Tissues were pretreated with $88 \%$ formic acid for $1 \mathrm{~min}$, sections were rinsed, followed by incubation with $3 \%$ hydrogen peroxidase for $5 \mathrm{~min}$, and then blocking of nonspecific labeling was performed in TBS with 5\% horse serum, 3\% $\mathrm{BSA}$, and $0.3 \%$ Triton $\mathrm{X}-100$. Sections were then rinsed and incubated overnight in anti-human A $\beta$ 6E10 antibody (1:1000; Covance). Sections were then treated sequentially with biotinylated horse anti-mouse secondary antibody, avidin-biotin solution (ABC Elite; Vector Laboratory), and nickel-enhanced diaminobenzidine. High-resolution digital images of the stained brain slices were obtained with a Nikon model Eclipse E400 $(4 \times)$. Plaques were clearly visible as darkly labeled bodies in the hippocampus and surrounding white matter. The total area of plaque coverage was measured using ImageJ in the region of the hippocampus and expressed as the percentage of plaque coverage area for each slice. $A \beta$ plaques were quantified in the hippocampus using a series of 1 in 12 sections per mouse.

Transmission electron microscopy. Hippocampi from WT and mutant hAPP Tg mice or snapin cKO mice were cut into small specimens (one dimension $<1 \mathrm{~mm}$ ) and fixed in Trumps fixative (Electron Microscopy Sciences) for $2 \mathrm{~h}$ at RT. The sections were then washed in $0.1 \mathrm{M}$ cacodylate buffer and postfixed in $1 \%$ osmium tetroxide, followed by dehydrating in ethanol, and embedding using the EMbed 812 kit (Electron Microscopy
Sciences) according to a stand procedure. Images were acquired on an electron microscope (100C X; JEOL; Electron Imaging Facility, Division of Life Sciences, Rutgers University, Piscataway, NJ). Quantification analysis was performed blind to condition.

\section{In vivo gene delivery}

The AAV2/9-mCherry and AAV2/9-mCherry-Snapin constructs were kindly provided by Z.-H. Sheng and as described previously (Xie et al., 2015). The AAV2/9-mCherry and AAV2/9-mCherry-Snapin viruses were produced by Vector BioLabs. Adult mutant hAPP Tg mice and WT littermates at 2-3 months of age were injected into the hippocampal dentate gyus (AP, $-2 \mathrm{~mm}$; L, $-1.5 \mathrm{~mm}$; DV , $+1.75 \mathrm{~mm}$ ) of both cerebral hemispheres according to the stereotaxic atlas of Franklin and Paxinos (2001) using $4-8 \times 10^{9}$ total viral particles per side and analyzed 5-8 months after injection.

\section{Behavioral assessments}

Male mice only were subjected to assessment for cognitive and emotional behavior. All tests were conducted with experimenters blind to genotype and treatment condition of the mice. Groups contained 7-14 mice per group for each behavioral test. Open field, elevated plus maze (EPM), and novel object recognition tests were performed in mice at $7-8$ months of age. The MWM and contextual fear conditioning were carried out in 8- to 11-month mice. All tests used the ANY-maze video tracking system (Stoelting), with additional video review by experimenters blind to group condition.

Open field test. This test involved measurement of spontaneous locomotor activity and within-session habituation to a novel environment. Mice were placed in clear plastic chambers $(62 \times 56 \times 28 \mathrm{~cm})$ for $5 \mathrm{~min}$. Total movements (ambulations) in the outer periphery and center (inner region of the open field, away from the periphery) of the open field were automatically recorded. The apparatus was thoroughly cleaned with $70 \%$ ethanol between trials.

Elevated plus maze. The elevated plus maze consisted of two open arms (without walls; $24.5 \times 7.5 \mathrm{~cm}$ ) and two enclosed arms (with high walls; $24.5 \times 16.5 \times 21 \mathrm{~cm}$ ); the maze was elevated $76 \mathrm{~cm}$ above the floor. Initiation of testing involved placing mice in the center region, which was the junction between the open and closed arms of the plus maze. Mice were allowed to explore the EPM for $5 \mathrm{~min}$. Entries were defined as the body center of the mouse entering a given zone (open arm, closed arm). Anxiety-related behavior was measured as the percentage of the time spent in the open arms (time in open arms divided by total time in both open and closed arms). The maze was thoroughly cleaned with $70 \%$ ethanol between testing sessions.

Novel object recognition. Mice were tested in the same apparatus used for open field testing $(62 \times 56 \times 28 \mathrm{~cm})$. During the training session, two identical objects were placed into the same chamber, and mice were allowed to explore the objects and the chamber for $5 \mathrm{~min}$. The entire procedure consisted of three 5 min trials with an intertrial interval of 15 min. Twenty-four hours later, the objects were replaced with one exact replica of the original object (e.g., golf ball) and a novel object (e.g., metal pipe) of different shape and texture, but similar in size to familiar object. Mice were then allowed to explore the objects and the chamber for 5 min. Behavior was recorded with ANY-maze. Recognition memory was assessed in the final trial in which time spent exploring each (original or novel) object was recorded for subsequent data analysis. Arenas and objects were cleaned with $70 \%$ ethanol after testing of each mouse.

Morris water maze. The water maze consisted of a pool $(110 \mathrm{~cm}$ in diameter) containing opaque water $\left(24 \pm 1^{\circ} \mathrm{C}\right)$ and a platform $(9.4 \mathrm{~cm}$ in diameter) submerged $1.5 \mathrm{~cm}$ under the water. Mice were trained to locate this hidden platform. Hidden-platform training (days 1-5) consisted of a total of 10 sessions (two sessions per day, spaced $3 \mathrm{~h}$ apart). Each session contained two trials with an intertrial interval of $10 \mathrm{~min}$. Mice were placed into the water with the head facing the tank wall and allowed a maximum of $60 \mathrm{~s}$ to find the hidden platform. A day after the last hiddenplatform training session, a memory probe trial was conducted by removing the platform and allowing mice to search for the platform in the pool for $60 \mathrm{~s}$. The time for mice to locate the hidden platform during 
learning, and the time in the target quadrant, path length, and swim speed during the probe tests, were calculated by the ANY-maze video tracking system.

Contextual fear conditioning. Conditioning was conducted in Coulbourn operant learning chambers that measured $17.8 \times 17.8 \times 30.5 \mathrm{~cm}$, and were located inside sound-attenuating cabinets (Coulbourn Instruments). The chamber contained a steel grid floor connected to a programmable shocker, while the walls were made of clear Plexiglas. For contextual fear conditioning, the mice were placed within the conditioning chamber for $3 \mathrm{~min}$ to develop a representation of the context, before the onset of a single unconditioned stimulus (footshock; $1 \mathrm{~s} / 1 \mathrm{~mA}$ ). Following the shock, they were allowed to remain in the chamber for 2 min, during which immediate freezing was measured continuously. Mice were then returned to the home cages. Memory was tested $24 \mathrm{~h}$ after training for $4 \mathrm{~min}$ in the same conditioning chamber. Animal movements were tracked with the ANY-maze video tracking system and motion detection software (Coulbourn Instruments).

\section{Statistics}

All statistical analyses were performed using GraphPad Prism 6. All data are presented as mean \pm SEM. Statistical significance was assessed by a paired or unpaired $t$ test (for two group comparisons), while two-way and repeated-measures one-way ANOVA tests with Tukey's post hoc comparisons were used for multiple comparisons. $p$ values less than or equal to 0.05 were considered statistically significant.

\section{Results}

BACE1 is aberrantly accumulated within presynaptic late endocytic organelles in mutant hAPP Tg mice and AD patient brains

BACE1 was reported to localize to dystrophic axons and presynaptic terminals in 5XFAD and 2XFAD mouse models and $\mathrm{AD}$ patient brains, which facilitates presynaptic $\mathrm{A} \beta$ generation (Zhang et al., 2009; Kandalepas et al., 2013; Sadleir et al., 2016). By purifying synapse-enriched synaptosomes using Percoll gradient centrifugation as described previously (DiGiovanni et al., 2012), we first determined whether APP amyloidogenic processing machinery is enriched in the synapse of hAPP Tg mouse brains harboring the human AD Swedish and Indiana mutations (CaMKII $\alpha$-tTA $\times$ tet-APPswe/ind; Jankowsky et al., 2005) at 12 months of age. Mutant hAPP Tg mouse brains displayed a significant increase in synaptosomal BACE1 $(15.28 \pm 4.25 ; p<0.05)$, Rab7, an LE marker (1.43 $\pm 0.17 ; p<0.05)$, APP (2.18 \pm 0.02 ; $p<0.001$ ), and with $\mathrm{C} 99$ and $\mathrm{A} \beta$, relative to those of their WT littermates. Importantly, $A \beta$ levels showed about a fourfold increase in Syn fractions compared to that of PNS fractions in AD mouse brains (Fig. 1A,B).

Consistent with previous studies (Zhang et al., 2009; Kandalepas et al., 2013; Buggia-Prévot et al., 2014; Sadleir et al., 2016), BACE1 is enriched, but with a relatively uniform pattern in the hippocampal mossy fibers of WT mouse brains. However, in the same region of hAPP Tg (J20) mouse brains harboring the human AD Swedish and Indiana mutations (Mucke et al., 2000), BACE1 was markedly clustered and accumulated: the average number of BACE1 clusters was increased in hAPP mice relative to that of WT mice (WT, $26.33 \pm 0.89$; hAPP, $75.76 \pm 3.71 ; p<$ 0.001 ; Fig. $1 C-E$ ). We next determined whether BACE1 is accumulated at presynaptic terminals of hAPP mice by performing coimmunostaining with antibodies against BACE1 and SYP, a synaptic vesicle protein used to label presynaptic terminals. We found that a majority of BACE1 clusters were colocalized with SYP-marked dystrophic presynaptic terminals in the hippocampal mossy fibers of hAPP mice (Fig. 1D). These BACE1 clusters were also colabeled by an antibody against CI-MPR, a membrane protein preferentially located in LEs (Griffiths et al., 1988; Fig.
$1 E)$. The average number of BACE1 clusters colocalized with SYP or CI-MPR in the hippocampal mossy fibers per imaging slice section was significantly increased in hAPP mice (SYP, $62.90 \pm$ 7.76; $p<0.001$; CI-MPR, $56.77 \pm 7.77 ; p<0.001$ ), compared to those of their WT littermate controls (SYP, $21.40 \pm 1.76$; CI-MPR, $18.50 \pm 1.44$; Fig. $1 F$ ). Moreover, a significant portion of BACE1 was colocalized with CI-MPR-labeled LEs at dystrophic presynaptic terminals surrounding amyloid plaques (Fig. $1 G$ ).

Using transmission electron microscopy (TEM), we assessed synaptic distribution of LEs at the ultrastructural level. Consistent with our observations from biochemical and immunohistochemical studies, we found a significant accumulation of LEs/ multiple vesicular bodies at the presynaptic terminals of hippocampal regions in hAPP mice, compared to WT littermates (WT, $4.0 \pm 2.45 \%$; hAPP, $34.29 \pm 6.49 \%$; $p<0.01$; Fig. $1 H, I$ ). We recently reported that BACE1 is accumulated within LEs in hAPP mouse brains (Ye and Cai, 2014). Together with our biochemical observation (Fig. $1 A, B)$ and light imaging data $(C-F)$, these data suggest that BACE1 is accumulated within late endocytic organelles at the presynaptic terminals of hAPP mouse brains, which may augment presynaptic APP amyloidogenic processing.

Given the fact that BACE1 level or its $\beta$ secretase activity is increased in AD patient brains (Yang et al., 2003; Fukumoto et al., 2004), we next addressed whether BACE1 is retained at the synaptic terminal of AD patient brains. By isolating synapseenriched synaptosomal fractions from the brain of age-matched controls and AD patients, we detected increased levels of BACE1 $(1.66 \pm 0.17 ; p<0.01)$ and LEs (1.34 $\pm 0.13 ; p<0.05)$, but no detectable changes in SNAP25, SYP, and PSD95 in AD synaptosomes compared to control subjects (Fig. $2 A, B$ ). Moreover, Snapin levels were not altered in AD patient brains relative to those in controls, particularly at synaptic terminals $(1.19 \pm 0.19 ; p=$ $0.50)$. Thus, this result provides additional evidence showing abnormal retention of BACE1 within synaptic late endocytic compartments in $\mathrm{AD}$ patient brains.

Compared to PNS fractions, PSD95 was relatively enriched in Syn fractions in the brain of both age-matched controls and $\mathrm{AD}$ patients (Fig. 2A). Moreover, the purity of the synaptosome preparations was further confirmed by less abundance of EEA1 and GAPDH relative to PNS fractions (Fig. $2 A$ ), which is consistent with the data from using fresh mouse brains (Fig. 1A). However, we did not detect significant enrichment of SNAP25 and SYP. It could be attributed to frozen postmortem human brain tissues in which synaptic preservation of SNAP25 and SYP is somehow partially compromised. With the same protocol, we showed that SYP and SNAP25 were relatively enriched in Syn factions prepared from fresh mouse brains (Figs. $1 A, 4 E$ ).

Synapse loss is expected in $\mathrm{AD}$ patient brains at certain stages of the disease. This is consistent with our observations showing a global reduction of synaptic proteins in $\mathrm{AD}$ patient brains compared to age-matched controls. The PNS fraction of the patient brain displayed a marked reduction in levels of SNAP25, SYP, and PSD95 at disease stage Braak III, suggesting the emergence of synapse loss (Fig. 2A). Synaptic proteins are highly enriched and possibly saturated in synaptosomes (Wu et al., 2011). Thus, when comparing the equal amount of synaptosomal preparations, the levels of SNAP25, SYP, and PSD95 in AD patients may not readily show significant change relative to those in control subjects (Fig. 2A,B). 

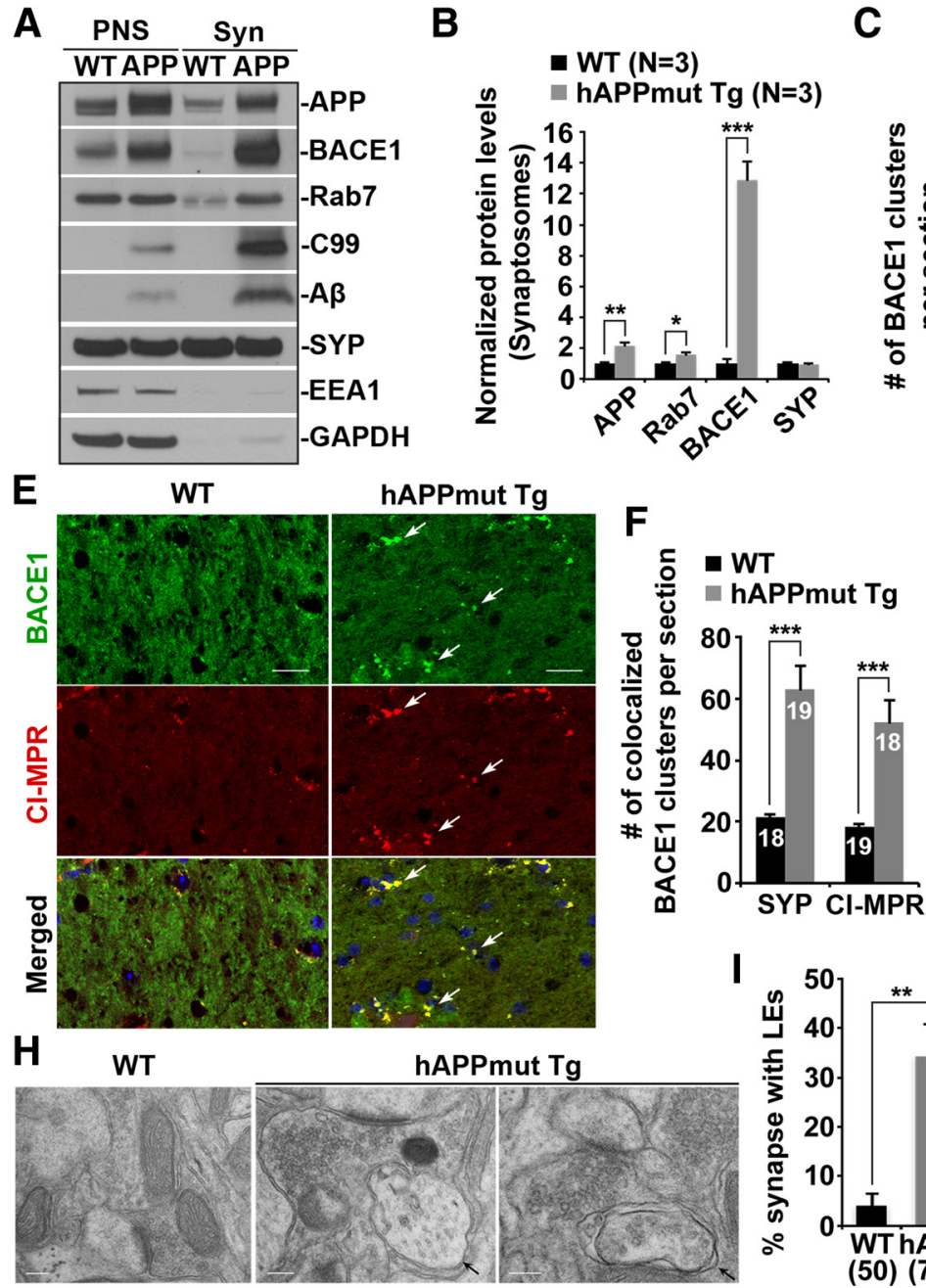

C
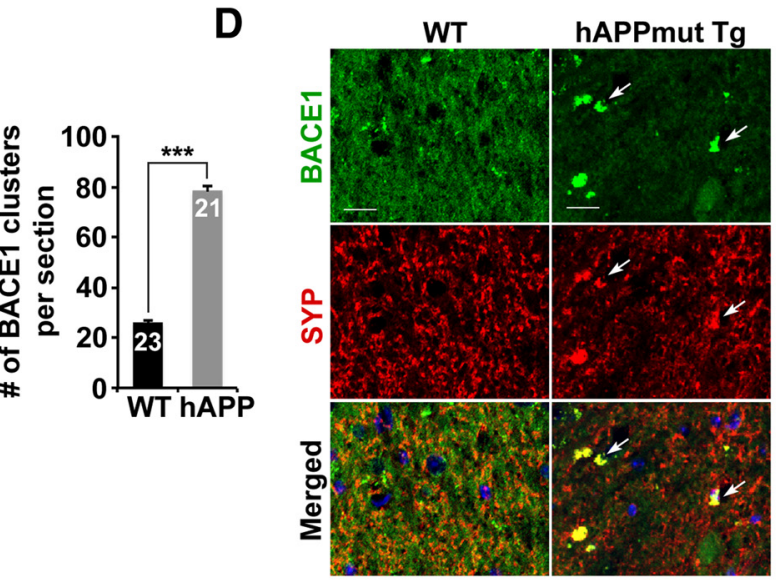

G
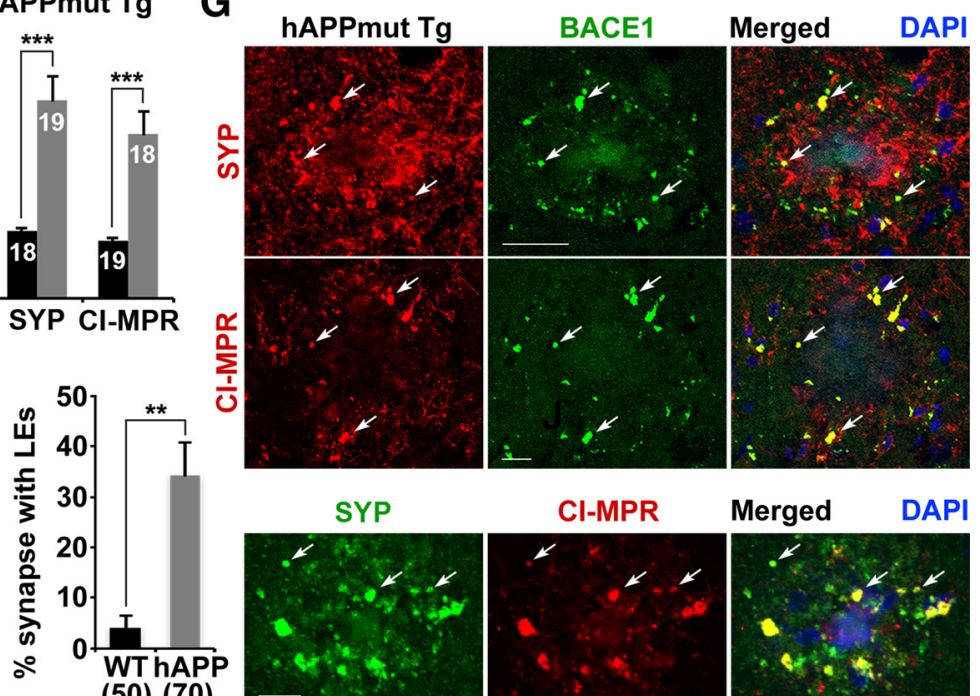

(50) (70)
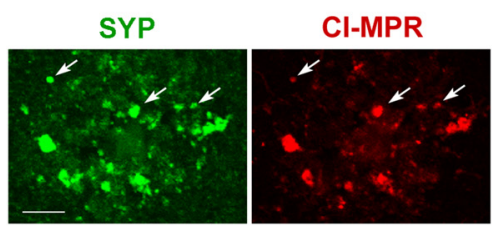

Merged

DAPI

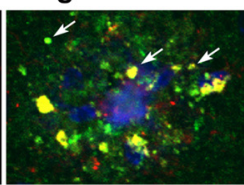

Figure 1. Aberrant accumulation of BACE1 within presynaptic late endocytic organelles in mutant hAPP Tg mice. $A, B$, Abnormal synaptic retention of BACE1 along with LEs, APP, C99, and A $\beta$ in mutant hAPP Tg mouse brains. Equal amounts $(15 \mu \mathrm{g})$ of synapse-enriched synaptosomal preparations (Syn) and postnuclear supernatants (PNS) from WT and hAPP mice were sequentially immunoblotted on the same membrane after stripping between each antibody application. The purity of synaptosomal fractions was confirmed by the absence of EEA1 and GAPDH. Data were quantified from three independent repeats. $\boldsymbol{C}-\boldsymbol{F}$, Quantitative analysis $(\boldsymbol{C}, \boldsymbol{F})$ and representative images $(\boldsymbol{D}, \boldsymbol{E})$ showing BACE1 accumulation within LEs and presynaptic terminals in the hippocampal region of mutant hAPP Tg (J20) mice. BACE1 clusters, indicated by white arrows, were not readily detected in WT mouse brains. Note that BACE1 clusters in the hippocampal mossy fiber regions of hAPP mice were colocalized with SYP-labeled presynaptic terminals and CI-MPR-marked LEs. The average numbers of BACE1 clusters and BACE1 colocalized with SYP and CI-MPR in the hippocampal mossy fibers per imaging slice section $(320 \times 320 \mu \mathrm{m})$ were quantified, respectively. Data were quantified from three pairs of mice, and total numbers of imaging slice sections are indicated at the tops of the bars $(\boldsymbol{C}, \boldsymbol{F}), \boldsymbol{G}, \mathrm{BACE} 1$ was accumulated within LEs at presynaptic terminals surrounding amyloid plaques of hAPP mice. $\boldsymbol{H}, \boldsymbol{I}$, Representative TEM images $(\boldsymbol{H})$ and quantitative analysis $(\boldsymbol{I})$ showing aberrant accumulation of LEs at axonal terminals in the hippocampal regions of hAPP mouse brains. LEs, indicated by black arrows, were not readily observed at WT synapses. The percentage of synapses containing LEs was quantified. Data were quantified from three pairs of mice, and the total numbers of EM fields $(10 \times 10 \mu \mathrm{m})$ are indicated in parentheses $(I)$. Scale bars: $\boldsymbol{D}, \boldsymbol{E}, 25 \mu \mathrm{m} ; \boldsymbol{G}, 10 \mu \mathrm{m} ; \boldsymbol{H}, 200 \mathrm{~nm}$. Error bars represent SEM. ${ }^{*} p<0.05 ;{ }^{* *} p<0.01 ;{ }^{* * *} p<0.001$ (Student's $t$ test).

Dynein-Snapin motor-adaptor complexes drive the retrograde transport of LE-loaded BACE1 in axons

Our previous study revealed that Snapin, as a motor adaptor, recruits dynein motors to LEs by interacting with the dynein intermediate chain (Cai et al., 2010). More recently, we also showed that Snapin mediates BACE1 retrograde transport in neurons (Ye and Cai, 2014). These findings suggest that Snapindynein motor coupling and retrograde transport may regulate BACE1 trafficking and distribution in distal axons and at presynaptic terminals. To address this question, we used snapin flox/flox cKO mice. Thy1-Cre Tg mice were used to generate snapin flox/ flox cKO mice, in which the snapin gene was deleted in neurons of the frontal cortex and hippocampus by Cre expression. We found that snapin-deficient mice displayed aberrant accumulation of BACE1 in the hippocampal mossy fibers that are composed of the axons and presynaptic terminals of granule cells in the dentate gyrus (Fig. 3A). The average number of BACE1 clusters was markedly increased in snapin-mutant mice relative to WT littermate controls (WT, $8.34 \pm 1.21$; snapin cKO, $57.58 \pm 5.53 ; p<$ 0.001 ; Fig. $3 A, B)$. Interestingly, a majority of BACE1 was colabeled by the LE marker CI-MPR, suggesting late endocytic retention of BACE1 in the distal axons of snapin-mutant neurons. Compared to WT littermates, the average number of BACE1 clusters that colocalized with CI-MPR per imaging slice section was increased in the hippocampal mossy fibers of snapin cKO mice (WT, $6.87 \pm 0.99$; snapin cKO, $52.89 \pm 5.36$; $p<0.001$; Fig. $3 \mathrm{~A}, \mathrm{C})$. However, we did not detect any significant change in the colocalized mean intensity of BACE1 with the dendritic marker MAP2 (1.08 $\pm 0.17 ; p>0.05)$, which suggests predominant accumulation of BACE1 within snapin-deficient axons (Fig. 3D,E).

To confirm our imaging data from snapin-mutant mouse brains, we next performed immunoisolation assays to purify 
A
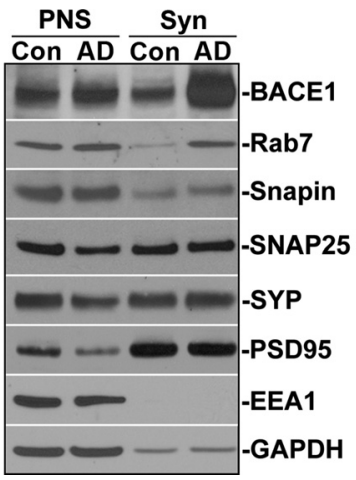

B

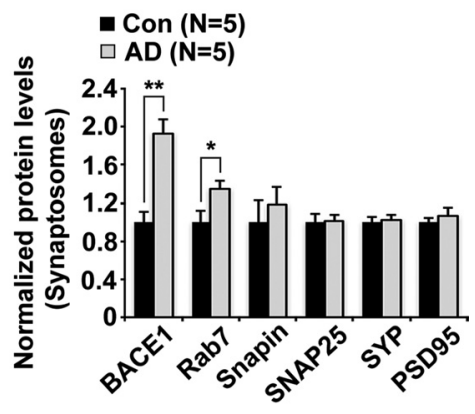

Figure 2. Synaptic retention of BACE1 and LEs in AD patient brains. $\boldsymbol{A}, \boldsymbol{B}$, Representative blots $(\boldsymbol{A})$ and quantitative analysis $(\boldsymbol{B})$ showing that BACE1 and LEs were accumulated at synaptic terminals in AD patient brains. Equal amounts (15 $\mu \mathrm{g})$ of synapseenriched synaptosomal preparations and postnuclear supernatants from human brains of control subjects and AD patients were sequentially immunoblotted on the same membrane after stripping between each antibody application. The purity of synaptosome fractions was confirmed by less abundance of EEA1 and GAPDH compared to that in PNS fractions. Data were quantified from five independent repeats. Error bars represent SEM. ${ }^{*} p<0.05 ;{ }^{* *} p<0.01$ (Student's $t$ test).

LEs using anti-Rab7-coated magnetic beads. When equal amounts of LEs - as reflected by Rab7 levels - were loaded, the normalized intensity of dynein DIC in snapin cKO mouse brains was significantly reduced to $\sim 55 \%$ of that seen in WT littermates ( $p<0.01$; Fig. $3 F, G)$, indicating reduced loading of the dynein motors onto LEs. The significantly reduced but not abolished DIC recruitment to LEs in snapin cKO mouse brains may suggest a compensatory role of (1) other dynein adaptors in LE-dynein coupling or (2) the remaining Snapin expressed in other types of cells in the mouse brain. In snapin cKO mouse brains, we detected a large amount of BACE1 from purified LEs $(2.73 \pm 0.48 ; p<0.05)$ relative to that of WT littermate controls (Fig. $3 F, G$ ), suggesting that BACE1 is retained within LEs in snapin-deficient mice.

\section{Presynaptic BACE1 retention enhances $\mathrm{A} \beta$ generation in snapin-deficient mouse brains}

To determine whether defective retrograde transport leads to abnormal accumulation of BACE1 at presynaptic terminals, we performed three lines of experiments using snapin flox/flox cKO mice. First, we performed a TEM study and demonstrated that LEs were aberrantly accumulated at presynaptic terminals after genetic ablation of snapin in mice. The average number of presynaptic LEs was increased compared to that of WT mice (WT, $12.24 \pm 1.03$; snapin cKO, $44.08 \pm 3.38$; $p<0.001$; Fig. $4 A, B)$. Second, by performing immunostaining, we found that the density of BACE1 clusters that colocalized with presynaptic marker SYP was markedly increased in the hippocampal mossy fiber regions of snapin cKO mice compared to that of their littermate controls (average number per imaging slice section, WT, $7.63 \pm$ 1.39; snapin cKO, $53.45 \pm 6.18$; $p<0.001$; Fig. $4 C, D)$. Moreover, $\sim 86.19 \%$ of these BACE1 clusters were accumulated within presynaptic terminals of snapin cKO mouse brains. Third, we purified synaptosomal fractions from WT and snapin cKO mice and further showed that snapin-deficient mice exhibited aberrant accumulation of BACE1 and LEs along with APP (BACE1:, 5.11 \pm 0.27, $p<0.01$; Rab7, $1.74 \pm 0.48, p<0.05$; APP, $4.08 \pm 0.45$, $p<0.01$ ) relative to their WT littermate controls (Fig. $4 E, F$ ).

Given that late endocytic organelles have an acidic environment optimal for the $\beta$ secretase activity (Huse et al., 2000; Koh et al., 2005; Tesco et al., 2007; Ye and Cai, 2014), we next tested whether late endocytic retention of BACE1 enhances synaptic $A \beta$ production in snapin cKO mouse brains. ELISAs in 1-month-old conditional snapin-deficient mice displayed a dramatic increase of mouse $\mathrm{A} \beta 40$ levels in the cerebral cortex (107.36 \pm $19.36 \% ; p<0.01)$ compared to their littermate controls. Increased levels of $\mathrm{A} \beta 40$ were also detected in the hippocampus in snapin-deficient mice (data not shown). Next, we measured and compared mouse $\mathrm{A} \beta$ levels in PNS and synaptosome factions from the same control or snapin cKO mice. Consistent with a recent study showing enhanced APP-BACE1 interaction at synaptic terminals and thus $\beta$ cleavage of APP (Das et al., 2016), we found that synapse-enriched fractions exhibited higher levels of $\mathrm{A} \beta 40$ in control mice compared to those in PNS fractions from the same mice (Syn, $56.80 \pm$ $13.85 \% ; p<0.05)$. Interestingly, synaptic A $\beta 40$ levels were further elevated in snapin cKO mice (Syn, $109.97 \pm 17.36 \%$; $p<0.01$ ), which is far above the basal synaptic A $\beta$ levels in control mice (Fig. 4G). These data suggest an increase in synaptic $A \beta$ generation in snapin-deficient neurons, which is attributed to late endocytic retention of BACE1 and augmented $\beta$ cleavage of APP at presynaptic terminals. Therefore, our observations indicate that Snapinmediated retrograde transport regulates presynaptic localization of BACE1 by facilitating the removal of late endosomal BACE1 from the distal axons. Defective retrograde transport induces BACE1 accumulation at presynaptic late endocytic compartments and thus elevates $\beta$ secretase activity for $\mathrm{A} \beta$ generation.

\section{Overexpressing Snapin in AD neurons facilitates BACE1 trafficking and reduces presynaptic $B A C E 1$ retention} Impaired retrograde transport in snapin $\mathrm{KO}$ neurons triggers BACE1 retention at presynaptic terminals, which allows us to propose a hypothesis: $\mathrm{AD}$ neurons display an impaired retrograde transport of BACE1; elevated Snapin expression can shift the balance from BACE1 retention in distal axons to trafficking toward the soma, thus reducing its presynaptic accumulation. To test this hypothesis, we first assessed the retrograde transport of LEs and BACE1 in live mutant hAPP Tg neurons. In WT neurons, a significant portion of Rab7-labeled LEs moved in the retrograde direction toward the soma $(31.78 \pm 2.22 \%)$, while BACE1 colocalized and comigrated with LEs along the same axon. However, in $\mathrm{AD}$ neurons, LEs displayed reduced retrograde motility in distal axons $(11.94 \pm 2.11 \% ; p<0.001)$. Such reduction was not found in the anterograde transport of LEs ( $p>0.05$; Fig. $5 A, B)$. Interestingly, BACE1-loaded LEs in hAPP neurons displayed a similar motility pattern, with reduced retrograde (15.76 \pm $2.27 \%$; $p<0.001)$, but not anterograde transport $(p>0.05)$ within the same axons (Fig. $5 A, B$ ). We next examined whether Snapin could rescue these phenotypes. Overexpressing Snapin increased retrograde transport of late endosomal BACE1 along hAPP axons $(43.28 \pm 3.12 \%$; $p<0.001)$, but did not affect its anterograde transport motility $(p>0.05)$. This biased enhancement of retrograde transport may facilitate the removal of late endocytic BACE1 from distal AD axons and presynaptic terminals. We next determined whether enhanced retrograde transport rescues abnormal LE accumulation at presynaptic terminals in mutant hAPP Tg neurons. LEs were clustered along hAPP axons as evidenced by increased LE density (per $100 \mu \mathrm{m}$ axons, WT, $12.47 \pm 0.91$; hAPP, $23.3 \pm 1.57 ; p<0.001$ ). Consistently, 

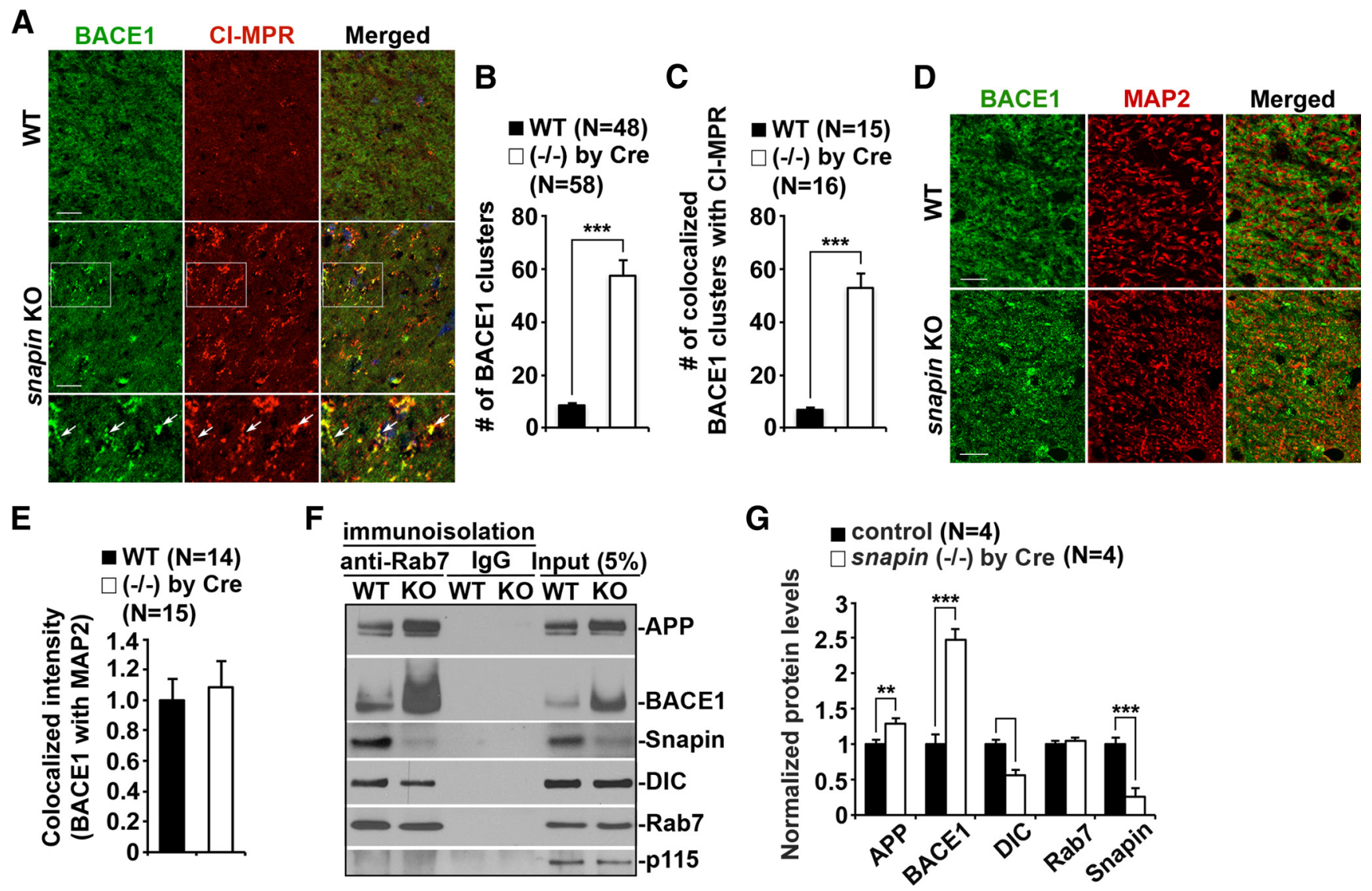

Figure 3. Dynein-Snapin motor-adaptor complexes drive the retrograde transport of LE-loaded BACE1 in axons. $\boldsymbol{A}-\boldsymbol{C}$, Representative images $(\boldsymbol{A})$ and quantitative analysis $(\boldsymbol{B}, \boldsymbol{C})$ showing $B A C E 1$ retention within late endocytic organelles in the hippocampal mossy fibers of snapin flox/flox cKO mice. Note that BACE1 clusters colocalized with Cl-MPR-labeled LEs were accumulated. BACE1 clusters, indicated by white arrows, were not readily observed in WT mouse brains. A BACE1 cluster was defined as a punctum with an area of at least $1.5 \times 1.5 \mu \mathrm{m}^{2}$ for analysis. The numbers of BACE1 clusters and BACE1 colocalized with Cl-MPR in the hippocampal mossy fibers per imaging slice section $(320 \times 320 \mu \mathrm{m})$ were quantified, respectively. Data were quantified from a total number of imaging slice sections, indicated in parentheses (B, C. D, E, Representative images $(\boldsymbol{D})$ and quantitative analysis $(\boldsymbol{E})$ showing that BACE1 was accumulated in MAP2-negative axons of snapin CKO mouse brains. The mean intensity of BACE1 colocalization with MAP2 was quantified. Data were quantified from a total number of imaging slice sections, indicated in parentheses (E). $\boldsymbol{F}, \mathbf{G}$, Immunoisolation showing robustly increased levels of BACE1 within LEs and reduced dynein motor attachment to LEs in snapin cKO mouse brains. Rab7-associated organelles were immunoisolated with anti-Rab7-coated Dyna magnetic beads, followed by sequential immunoblotting on the same membranes after stripping between each antibody application. Data were quantified from four independent repeats. Scale bars: $25 \mu \mathrm{m}$. Error bars represent SEM. ${ }^{* *} p<0.01 ;{ }^{* * *} p<0.001$ (Student's $t$ test).

the density of LE-enriched presynaptic terminals was significantly increased in hAPP neurons relative to that of WT controls (per $100 \mu \mathrm{m}$ axons, WT, $6.94 \pm 0.51$; hAPP, $19.18 \pm 1.64$; $p<0.001)$. Elevated Snapin expression in AD neurons led to a robust reduction in LE density in distal axons $(9.99 \pm 0.6$; $p<$ $0.001)$ and thus reversed LE retention at the presynaptic terminals $(6.22 \pm 0.43 ; p<0.001$; Fig. $5 C, D)$.

The balance of BACE1 trafficking and synaptic retention significantly influence its $\beta$ secretase activity and $\mathrm{A} \beta$ production (Buggia-Prévot and Thinakaran, 2015). We next asked whether Snapin-enhanced retrograde transport shifts this balance by facilitating BACE1 trafficking and thus reducing its localization at the presynaptic terminals of hAPP neurons. Specially, we evaluated the trafficking pattern of BACE1 that pauses at or passes by synapses along axons. Compared to WT neurons, BACE1 was increasingly retained at the synapses of hAPP neurons as a result of an increased stationary pool of BACE1 (WT, $34.16 \pm 2.37 \%$; hAPP, $52.94 \pm 3.08 \%$; $p<0.001$ ). In hAPP neurons, impaired retrograde transport resulted in less BACE1 moving out of synapses (WT, $23.58 \pm 1.71 \%$; hAPP, $8.52 \pm 1.44 \%$; $p<0.001$ ) and passing by synapses (WT, $12.44 \pm 1.45 \%$; hAPP, $5.02 \pm 1.0 \%$; $p<0.001)$. Thus, enhanced BACE1 retention at presynaptic terminals can be attributed to the altered pattern of BACE1 traffick- ing in hAPP axons. Importantly, Snapin-enhanced retrograde transport reduced synaptic BACE1 accumulation by facilitating the BACE1 trafficking and thus removing it from the presynaptic terminals of hAPP neurons $(22.81 \pm 1.21 \%$; $p<0.001$; Fig. $5 E, F)$. Given that presynaptic terminals are known as a major site for $\mathrm{A} \beta$ generation (Coleman and Yao, 2003; Mucke and Selkoe, 2012; Buggia-Prévot and Thinakaran, 2015), our findings allow us to propose that Snapin-mediated retrograde transport may attenuate BACE1 cleavage of APP and $\mathrm{A} \beta$ production at presynaptic terminals of $\mathrm{AD}$ neurons by reducing $\mathrm{BACE} 1$ retention.

\section{Enhanced BACE1 retrograde transport attenuates synapse} loss in mutant hAPP Tg mouse brains

$\mathrm{A} \beta$ accumulation at nerve terminals is highly correlated with synaptic damage in AD brains (Mucke et al., 2000; Tampellini et al., 2010, 2011; Takahashi et al., 2013). We hypothesized that Snapin-enhanced retrograde transport reverses synaptic BACE1 retention and reduces $\mathrm{A} \beta$ generation, thus attenuating synaptic pathology in $\mathrm{AD}$ neurons. To test our hypothesis in vivo, we overexpressed Snapin in the mutant hAPP Tg mouse brains at the age of 2-3 months by bilateral injection of AAV-mCherry-IRESSnapin into the hippocampus, an established in vivo delivery procedure (Nagahara et al., 2009, 2013; Xiao et al., 2015). The 
A

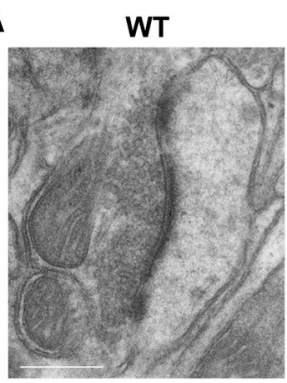

D

- WT $(\mathbf{N}=20)$

$\square(-I-)$ by Cre $(\mathbf{N}=27)$

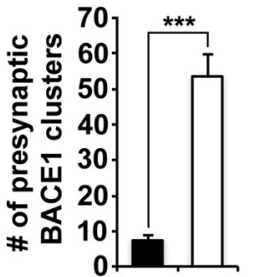

F

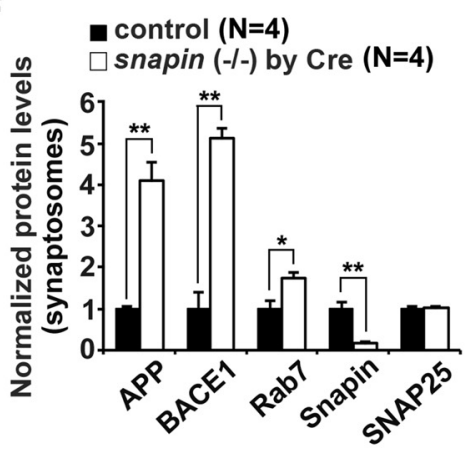

E
B
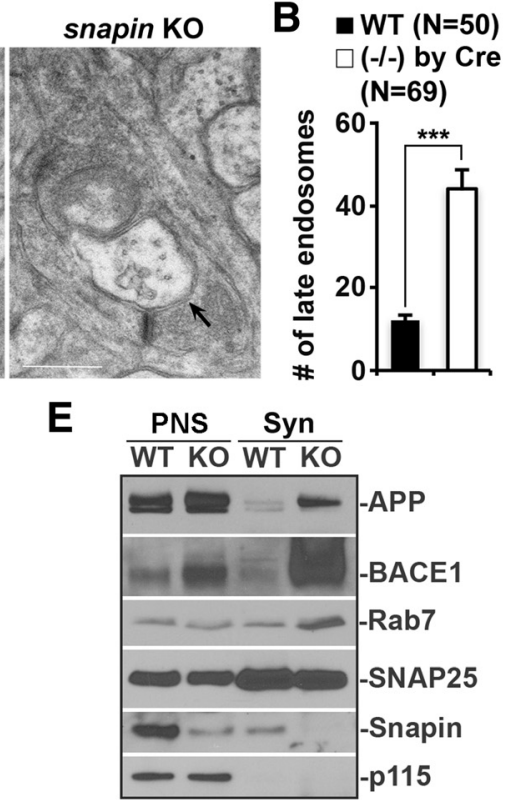

G

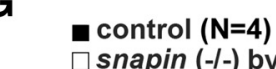

control $(\mathrm{N}=4)$
$\square$ snapin $(-/-)$ by
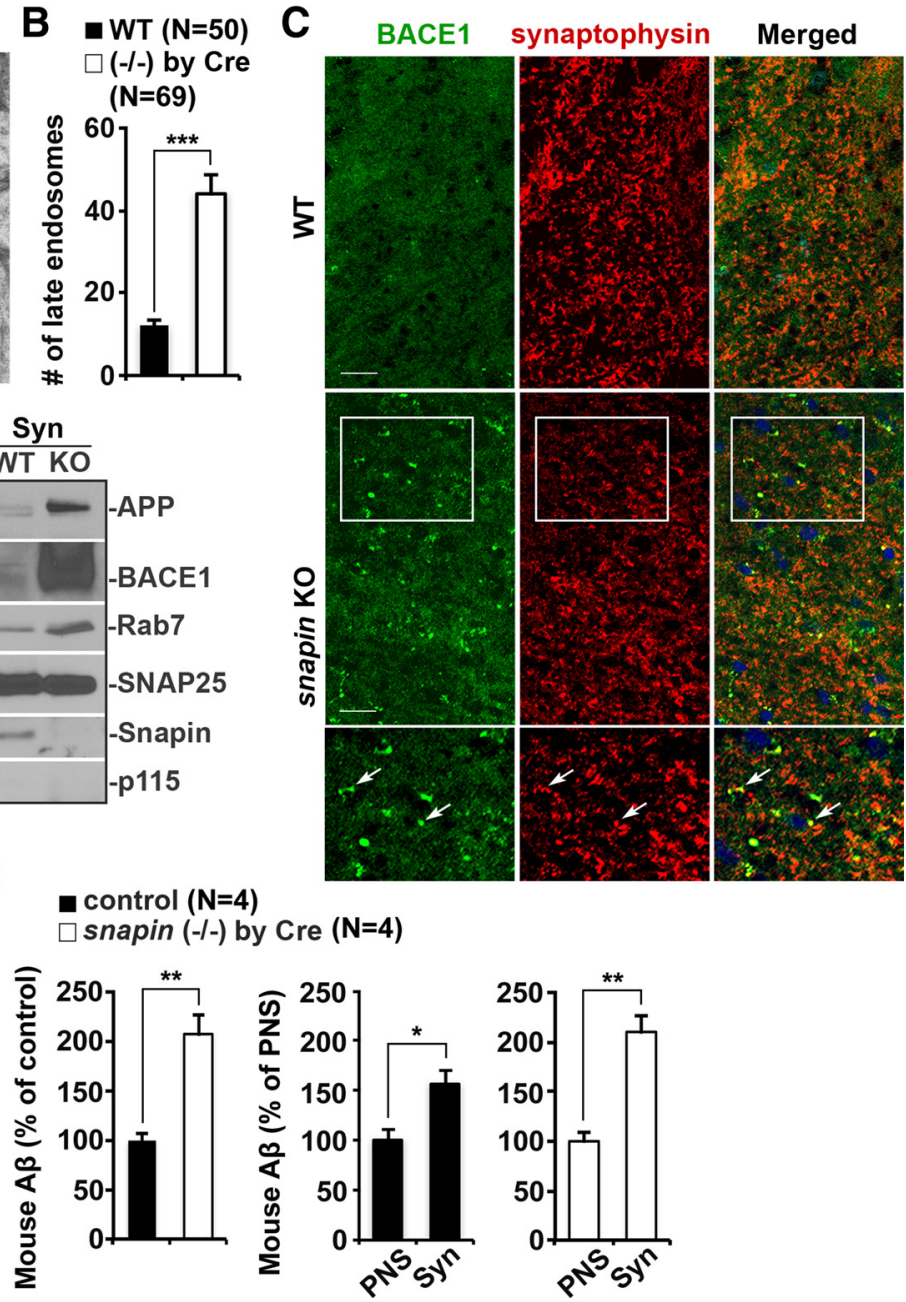

Figure 4. Presynaptic BACE1 retention enhances $A \beta$ generation in snapin-deficient mouse brains. $\boldsymbol{A}, \boldsymbol{B}$, Representative TEM images $(\boldsymbol{A})$ and quantitative analysis $(\boldsymbol{B})$ showing aberrant accumulation of LEs (black arrows) at the presynaptic terminals in snapin-deficient mice. LEs were not readily detected in WT synapses. The average number of LEs per EM field (10 $\times 10 \mu \mathrm{m}$ ) was quantified. Data were quantified from three pairs of mice and from a total number of EM fields, indicated in parentheses $(\boldsymbol{B})$. $\boldsymbol{C}, \boldsymbol{D}$, Representative images $(\boldsymbol{C})$ and quantitative analysis $(\boldsymbol{D})$ showing presynaptic BACE1 retention (white arrows) in the hippocampal mossy fibers of 1-month-old snapin cKO mouse brains. $\boldsymbol{E}$, $\boldsymbol{F}$, Aberrant accumulation of BACE1 and LEs along with APP in the synaptic terminals of snapin cKO mice. Equal amounts (15 $\mu \mathrm{g}$ ) of synapse-enriched synaptosomal preparations and postnuclear supernatants from WT and snapin cKO mice were sequentially immunoblotted on the same membrane after stripping between each antibody application. The purity of synaptosomal fractions was confirmed by the absence of p115, a Golgi marker. Data were quantified from four independent repeats. $\mathbf{G}, A \beta$ was more concentrated in the synapse purified from snapin-deficient mouse brains. Cerebral cortices with guanidine $\mathrm{HCl}$ extraction buffer or synaptosomal preparations and PNS from mouse cortices were homogenized, and, by ELISA assay, mouse A $\beta 40$ levels were analyzed in 1-month-old snapin cKO mouse cortex homogenates and compared to those of their littermate controls ( $N=4$ for each of the genotypes). The concentration of A $\beta 40$ in Syn was compared with and normalized to that in PNS from the same control or snapin cKO mice. Scale bars: $\boldsymbol{A}, 500 \mathrm{~nm} ; \boldsymbol{C}, 25 \mu \mathrm{m}$. Error bars represent SEM. ${ }^{*} p<0.05 ;{ }^{* *} p<0.01$; ${ }^{* * *} p<0.001$ (Student's $t$ test).

majority of neurons in the hippocampal dentate gyrus were infected (Fig. 6D). We first examined BACE1 distribution in the granule cells of the dentate gyrus and their processes in hippocampal mossy fibers of WT and mutant hAPP Tg mouse brains injected with AAV-Snapin or AAV control. In WT mice, BACE1 signals appeared as vesicular structures in the soma of dentate granule cells, but were in much smaller fine structures within their processes in the hippocampal mossy fibers (Fig. 6A). Compared to WT mice, BACE1 in hAPP mice displayed reduced fluorescence intensity in the soma of granule cells $(0.75 \pm 0.01 ; p<$ $0.001)$, but were accumulated and clustered into larger structures in the mossy fiber areas $(74.67 \pm 2.29 ; p<0.001$; Fig. $6 A-C)$. However, in hAPP mice transduced with AAV-Snapin, BACE1 targeting to the soma was markedly increased ( $0.94 \pm 0.01 ; p<$ 0.001 ) along with a significant decrease in axonal accumulation of BACE1 (33.87 $\pm 1.46 ; p<0.001)$. Our in vivo data suggest that elevated Snapin expression facilitates the delivery of BACE1 to the soma, thus reducing BACE1 retention in distal axons and presynaptic terminals of hAPP Tg mouse brains.

We next determined whether reduced BACE1 accumulation and $\beta$ cleavage of APP in distal axons mitigates synaptic pathology. Consistent with previous studies on hAPP (J20) mice (Mucke et al., 2000), we found that SYP-labeled presynaptic terminals were significantly reduced in the hippocampal mossy fiber regions of hAPP mice, relative to those of WT mice (WT, $37.96 \pm$ $0.93 \%$; hAPP, $28.27 \pm 1.08 \%$; $p<0.001$ ), suggesting synapse loss in hAPP mouse brains. However, synapse loss was attenuated in hAPP mice injected with AAV-Snapin $(34.22 \pm 0.83 \%$; $p<$ 0.001; Fig. 6E,F). Elevated Snapin expression following AAVSnapin injection was verified by western blot analysis of hippocampal homogenates, which revealed increased Snapin levels in the hippocampus in Snapin-injected WT or hAPP mice (WT, $1.92 \pm 0.13, p<0.05$; hAPP, $1.79 \pm 0.10, p<0.05)$ relative to $\mathrm{WT}$ or hAPP mice transduced with AAV control (Fig. $6 G, H$ ). Thus, 

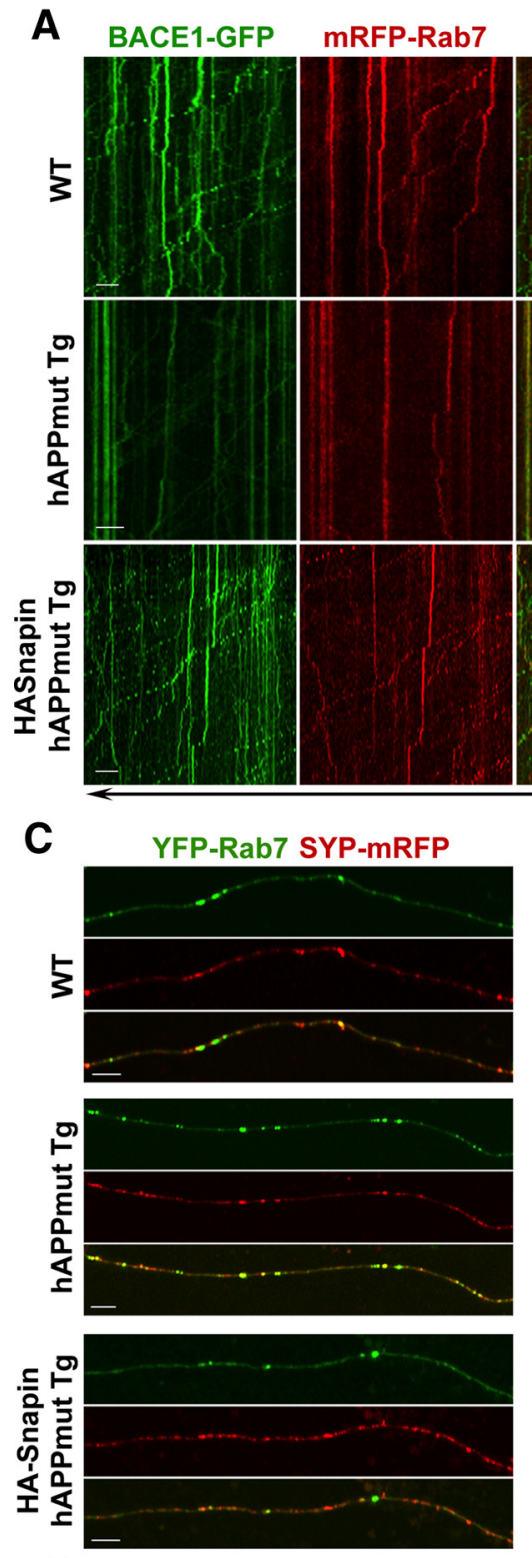

D

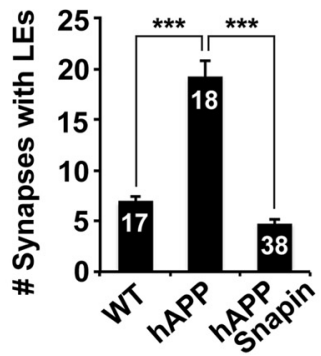

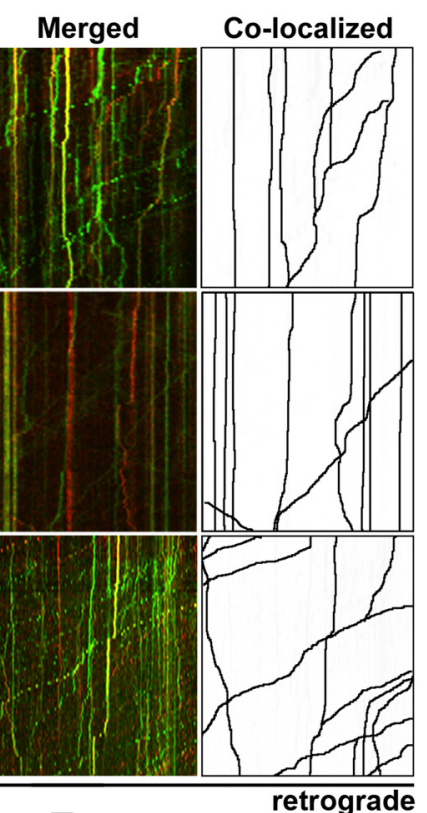

B

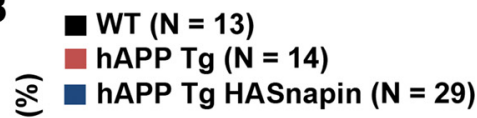

tั 100
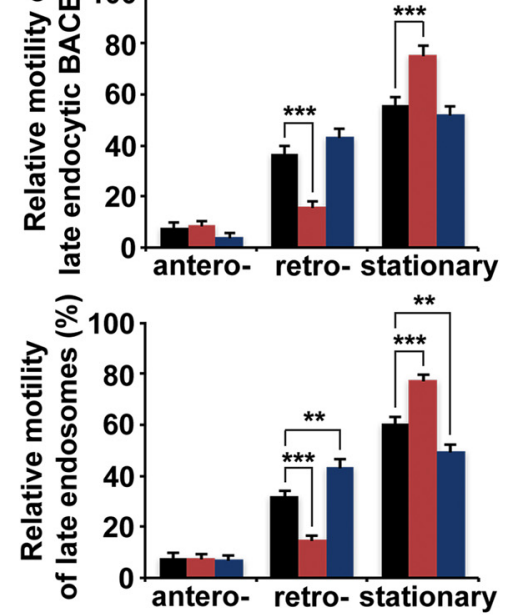

HA-Snapin

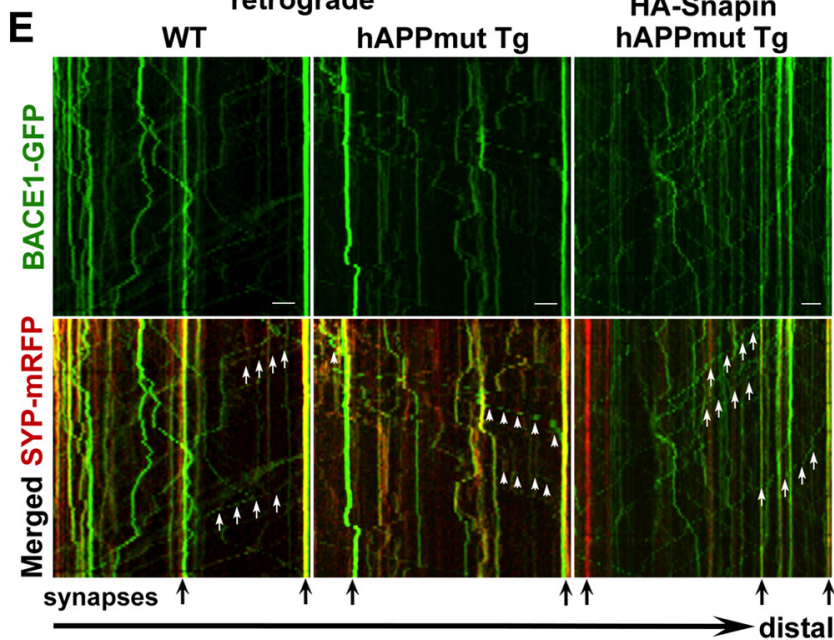

$F \quad \square T(N=12 ; V=892)$

hAPP $\operatorname{Tg}(\mathrm{N}=12 ; \mathrm{V}=761)$

hAPP Tg HASnapin $(\mathrm{N}=15 ; \mathrm{V}=693)$

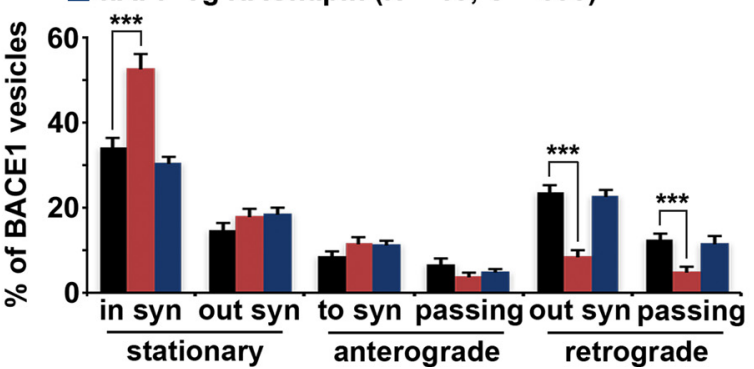

Figure 5. Overexpressing Snapin in AD neurons facilitates BACE1 trafficking and reduces presynaptic BACE1 retention. $A, B$, Dual-channel kymographs showing impaired retrograde transport of late endosomal BACE1 in mutant hAPP Tg axons, which was reversed by overexpression of Snapin. Vertical lines represent stationary organelles. Lines slanted to the right (negative slope) represent anterograde movement; lines slanted to the left (positive slope) indicate retrograde movement. An organelle was considered stationary if it remained immotile (displacement of $\leq 5 \mu \mathrm{m}$ ). The majority of BACE1-assoicated LEs remained stationary in the axons of hAPP neurons, whereas elevated Snapin expression selectively increased retrograde but not anterograde transport of BACE1-associated LEs. WT or hAPP neurons were cotransfected with BACE1-GFP and mRFP-Rab7 or with HA-Snapin at DIV 6, followed by time-lapse imaging at DIV 9 -10. Data were quantified from a total number of neurons indicated in parentheses $(\boldsymbol{B})$ and from at least three independent experiments. $\boldsymbol{C}, \boldsymbol{D}$, Representative images $(\boldsymbol{C})$ and quantitative analysis $(\boldsymbol{D})$ showing that Rab7-labeled LEs were accumulated in distal axons and presynaptic terminals of hAPP neurons. Elevated Snapin expression reduced LE accumulation at presynaptic terminals. Data were quantified from the total number of neurons indicated at the top of bars $(\boldsymbol{D})$ and from three independent experiments. $\boldsymbol{E}, \boldsymbol{F}$, Representative kymographs $(\boldsymbol{E})$ and quantitative analysis $(\boldsymbol{F})$ showing multiple patterns of axonal BACE1 trafficking to or out of or passing by synapses. Relative populations of axonal BACE1 were quantified as (1) stationary out of synaptic sites (Out syn), (2) stationary at synaptic sites (In syn) during the recording time, (3) moving quickly, passing by boutons (passing), (4) motile moving to synapses (anterograde; arrow heads) and out of synapses (retrograde; arrows). Note that reduced BACE1 motility decreased its trafficking out of synaptic boutons (retrograde) and increased its retention at synapses in hAPP axons, which was reversed by elevated Snapin expression. Data were quantified from the total number of neurons, indicated in parentheses $(\boldsymbol{F})$, and from more than three independent experiments. Scale bars: $10 \mu \mathrm{m}$. Error bars represent SEM. ${ }^{* *} p<0.01$; ${ }^{* * *} p<0.001$ (Student's $t$ test). 


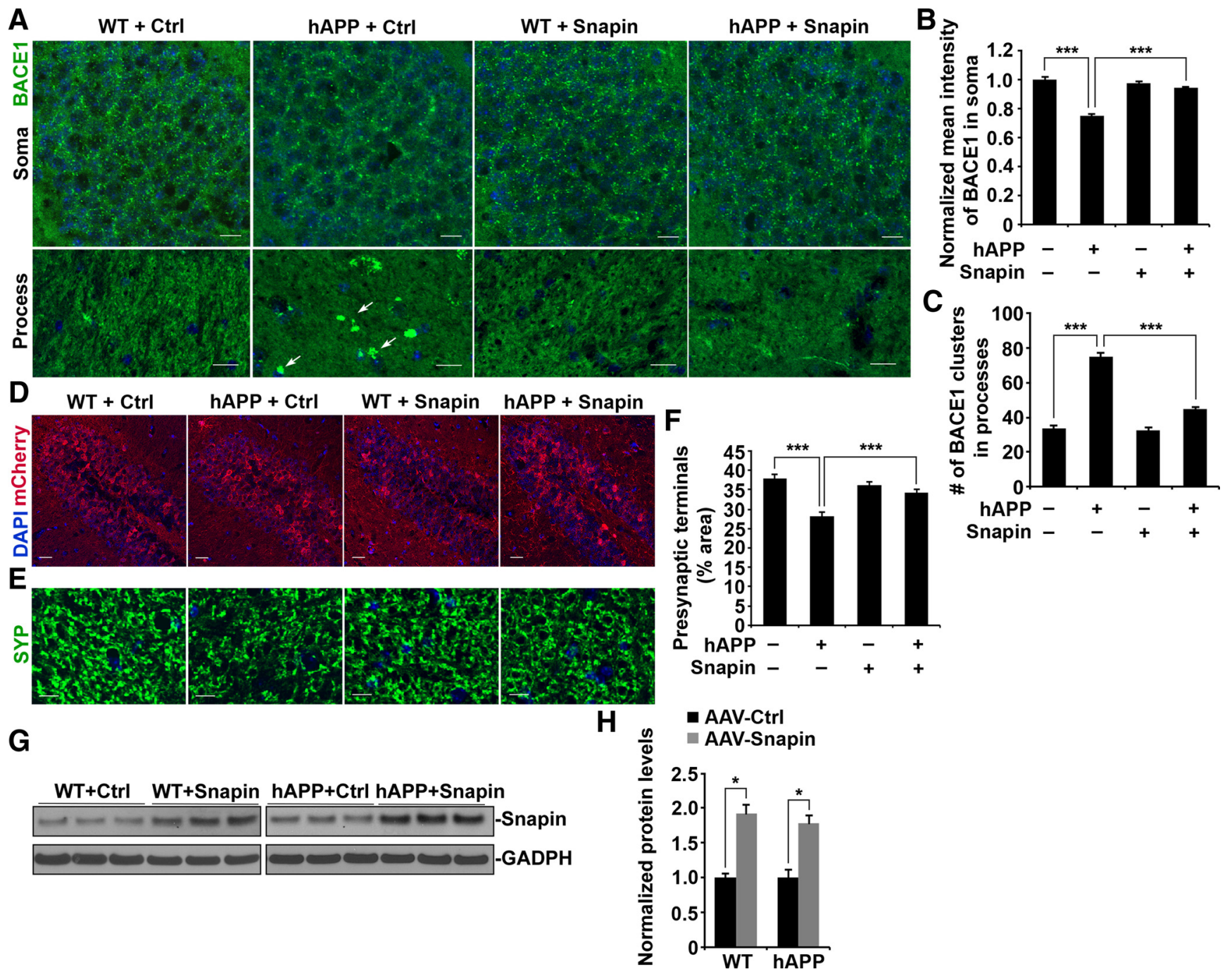

Figure 6. Enhanced BACE1 retrograde transport attenuates synapse loss in mutant hAPP Tg mouse brains. $\boldsymbol{A}-\boldsymbol{C}$, Representative images $(\boldsymbol{A})$ and quantitative analysis ( $\boldsymbol{B}, \boldsymbol{C})$ showing that elevated Snapin expression enhanced BACE1 targeting to the granule cells of dentate gyrus (soma) and thus reduced BACE1 clustering in the hippocampal mossy fibers (process) in mutant hAPP mice. BACE1 clusters, indicated by white arrows, were not readily detected in WT mouse brains. The mean intensity of BACE1 fluorescence in the dentate granule cells and the average number of BACE1 clusters in the hippocampal mossy fibers per imaging slice section $(320 \times 320 \mu \mathrm{m})$ were quantified from a total number of $40-68$ imaging slice sections per genotype, respectively. One-way ANOVA revealed a significant effect of hAPP ( $p<0.0001)$ relative to WT mice and the rescue effect of elevated Snapin expression on hAPP mice $(p<0.0001)$, but not on WT mice (BACE1 fluorescence in the soma, $p=0.2486$; BACE1 clusters, $p=0.5299)$. $D$, Gene delivery into hippocampus. mCherry fluorescence showed transduced neurons in the hippocampal dentate gyrus of WT and hAPP mice injected with AAV-mCherry or AAV-mCherry-Snapin. $\boldsymbol{E}, \boldsymbol{F}$, Elevated Snapin expression mitigated synapse loss. Note that presynaptic terminals in the hippocampal mossy fibers revealed by SYP immunostaining were significantly reduced in hAPP mice relative to those in WT mice $(p<0.0001)$. This reduction was attenuated in hAPP mice injected with AAV-Snapin $(p<0.0001$ by one-way ANOVA). The percentage area of SYP-labeled presynaptic terminals was quantified from a total number of 40 - 44 imaging slice sections per genotype. $\boldsymbol{G}, \boldsymbol{H}$, Representative blots $(\boldsymbol{G})$ and quantitative analysis $(\boldsymbol{H})$ showing elevated Snapin levels in the hippocampus of WT or hAPP mouse brains injected with AAV-Snapin. A total of $10 \mu \mathrm{g}$ of hippocampal homogenates from WT or hAPP mice injected with AAV control or AAV-Snapin was sequentially detected. Relative protein levels were normalized by GAPDH and to that of WT or hAPP mice injected with AAV control. Data were analyzed from three mice per genotype and are expressed as mean \pm SEM with Student's $t$ test. ${ }^{*} p<0.05 ;{ }^{* * *} p<0.001$. Scale bars: $A, D, 25 \mu \mathrm{m} ; \boldsymbol{E}, 10 \mu \mathrm{m}$.

these in vivo beneficial effects after elevated Snapin expression support the notion that Snapin-enhanced trafficking and reduced retention of BACE1 attenuates synaptic pathology in hAPP mouse brains.

Enhanced BACE1 retrograde transport reduces synaptic A $\beta$ levels in mutant hAPP Tg mouse brains

We further sought to address whether Snapin-mediated rescue on synaptic pathology results from decreased $\mathrm{A} \beta$ production. By performing ELISA assays, we found that human $A \beta 40$ in the hippocampus was much more concentrated in the synapse-enriched fractions relative to that in the PNS from the same hAPP Tg mice (synaptosomes, $369.12 \pm 63.55 \%$; $p<$ 0.01 ; Fig. $7 A$ ). We next measured intracellular $A \beta 40$ levels, in particular, synaptic $A \beta 40$ levels in the synapse-enriched synaptosomal preparations from the hippocampi of hAPP mouse brains infected with AAV-Snapin or AAV control. Elevating Snapin expression reduced the levels of synaptic $A \beta 40$ to $32.92 \%(p<0.05$; Fig. $7 B)$.

Next, we tested whether hAPP mice transduced with AAVSnapin exhibit the decrease in intracellular $A \beta$ as a result of increased BACE1 trafficking and turnover. By using the wellcharacterized A11 antibody that detects intracellular $A \beta$ oligomers, a soluble amyloid conformation, but not APP and its cleaved products C99 (Kayed et al., 2003; Jimenez et al., 2008, 2011; Zempel et al., 2010), we further showed that elevated Snapin expression reduces intracellular $\mathrm{A} \beta$ accumulation in the hippocampi of hAPP mice relative to controls $(39.92 \pm 1.67 \%$; $p<0.001$; Fig. 
A

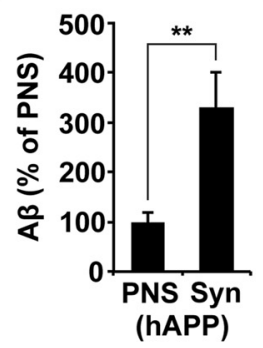

B

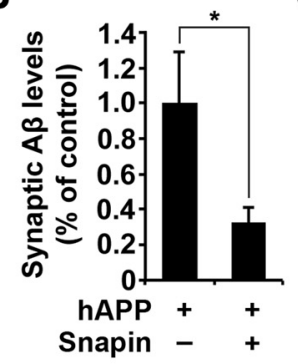

C

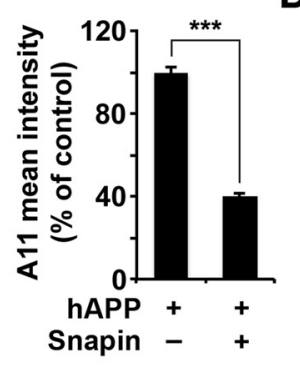

D

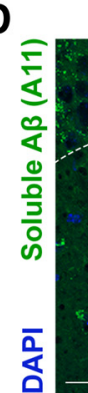

hAPP + Snapin

E
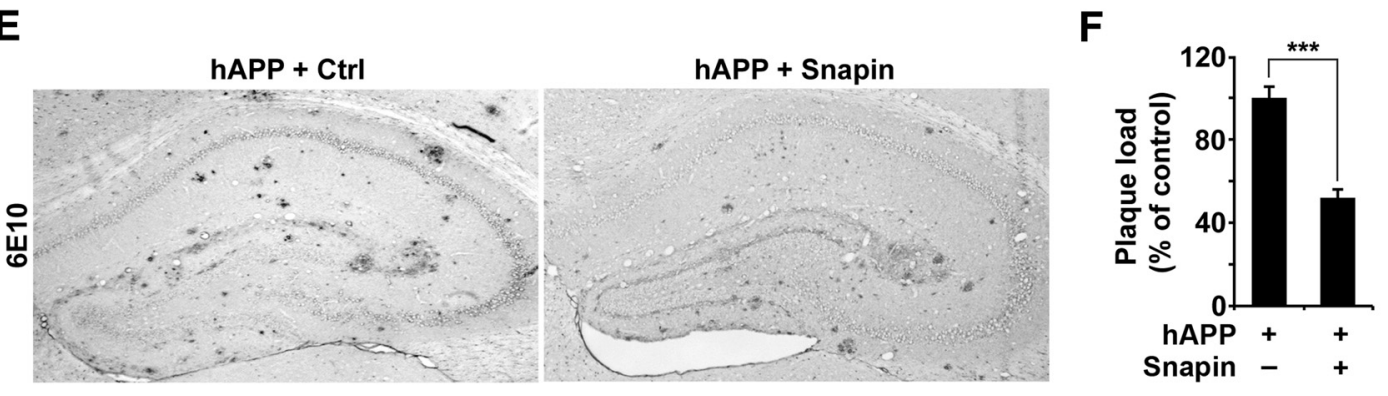

Figure 7. Enhanced BACE1 retrograde transport reduces synaptic $A \beta$ levels in mutant hAPP Tg mouse brains. $A$, Greater enrichment of $A \beta 40$ in the synapses of hAPP mouse brains. Human A $\beta 40$ levels were measured in the synapse-enriched synaptosomal preparations and postnuclear supernatants from hAPP mouse brains by ELISA assay $(n=6)$. The concentration of synaptic $A \beta 40$ in the hippocampus was compared with and normalized to that in PNS from the same hAPP mice. $\boldsymbol{B}$, Reduction of human A $\beta 40$ levels at synaptic terminals in the hippocampus of mutant hAPP mice transduced with AAV-Snapin ( $n=6$ for each genotype). $\boldsymbol{C}$, $\boldsymbol{D}$, Quantitative analysis $(\boldsymbol{C})$ and representative images $(\boldsymbol{D})$ of intracellular A $\beta$ in hAPP mice injected with AAV and AAV-Snapin. Note that elevated Snapin expression reduced aberrant accumulation of intracellular $A \beta$ in the hippocampal regions of $A D$ mice. White arrows marked soluble $A \beta$ clusters in the hippocampal mossy fibers of hAPP mice. The mean intensity of anti-A11-stained intracellular A $\beta$ oligomers was quantified and compared to that of controls from a total number of $56-57$ imaging slice sections per genotype. s.p., Stratum pyramidale; $\mathrm{mf}$, mossy fiber. $\boldsymbol{E}, \boldsymbol{F}$, Representative images $(\boldsymbol{E})$ and quantitative analysis $(\boldsymbol{F})$ showing reduced amyloid deposition in the hippocampal regions of hAPP mice expressing AAV-Snapin by immunostaining using anti-6E10 antibody. The percentage of plaque coverage area was quantified from a total number of 43- 47 imaging slice sections per genotype, and the results are expressed as the percent difference from hAPP mice injected with AAV control. Scale bars: $25 \mu \mathrm{m}$. Error bars represent SEM. ${ }^{*} p<0.05 ;{ }^{* *} p<0.01$; ${ }^{* * *} p<0.001$ (Student's $t$ test).

$7 C, D)$. Snapin-enhanced retrograde transport facilitates the removal of BACE1, and thus attenuates $\beta$ cleavage of APP in distal axons and presynaptic terminals. This observation is also consistent with our data showing decreased $A \beta$ levels at the synaptic terminals of hAPP mice transduced with AAV-Snapin (Fig. 7B). Given that abnormal $A \beta$ accumulation plays a key role in the development of synaptic pathology in AD (Mucke et al., 2000; Tampellini et al., 2010, 2011; Takahashi et al., 2013), our study indicates that Snapin-induced rescue on $\mathrm{AD}$-linked synaptic pathology is attributed to reduced synaptic $A \beta$ levels.

Accumulating evidence indicates that $\mathrm{A} \beta$ released from presynaptic terminals is the main source of extracellular amyloid deposits in AD mouse models and human patient brains (Lazarov et al., 2002; Sheng et al., 2002; Cumming et al., 2004; Luo and Yan, 2010; Dislich and Lichtenthaler, 2012). We next investigated whether reduced presynaptic $\mathrm{A} \beta$ impacts amyloid deposition. Interestingly, we detected a significant reduction in amyloid plaque formation after Snapin overexpression in hAPP mouse brains $(51.97 \pm 4.44 \%$; $p<0.001$; Fig. $7 E, F)$, thus indicating a beneficial effect of Snapin-mediated retrograde transport on the attenuation of amyloidogenesis.

\section{Elevated Snapin expression ameliorates cognitive deficits in mutant hAPP Tg mice}

Mounting evidence suggests that synapse loss correlates best with impaired learning and memory in AD (Sze et al., 1997; Hsia et al., 1999; Shankar and Walsh, 2009). Given the fact that Snapinenhanced retrograde transport ameliorates synapse loss (Fig. $6 E, F)$, we speculated that increasing Snapin expression in the hippocampus mitigates learning and memory deficits in hAPP mice. We next asked whether overexpression of Snapin prevents these behavioral abnormalities that are readily detectable in
hAPP mice. Seven- to eight-month-old mutant hAPP Tg mice displayed hyperactivity in the open field and lower levels of anxiety phenotype in the EPM (Chin et al., 2005; Harris et al., 2010; Cissé et al., 2011). Following AAV-mediated Snapin overexpression, there was no significant effect on the hyperactivity of hAPP mice in the open field ( $p>0.05$; Fig. $8 A$ ). This suggests the persistence of brain regions driving hyperlocomotor behavior, and which were resistant to Snapin modulation. Moreover, in the EPM test, a traditional measure of anxiety, hAPP mice spent more time in the open arms of the EPM relative to WT mice, suggesting lower levels of anxiety or disinhibition. While this result is in agreement with many previous studies (Chin et al., 2005; Cheng et al., 2007; Roberson et al., 2007; Meilandt et al., 2009), hAPP mice injected with AAV-Snapin did not significantly reverse this phenotype $(p=0.0791$ by two-way ANOVA test; Fig. $8 B$ ).

Like other hAPP Tg mice, hAPP J20 mice show deficits in spatial and nonspatial learning and memory (Cheng et al., 2007; Meilandt et al., 2009; Harris et al., 2010; Cissé et al., 2011). We first assessed the nonspatial learning and memory with the novel object recognition test. Apart from WT littermates with or without Snapin, hAPP mice did not prefer the novel over the familiar object, suggesting deficits in recognizing or remembering the familiar object. AAV-Snapin-injected hAPP mice spent more time exploring the novel object ( $p<0.0001$ by two-way ANOVA; Fig. $8 C$ ), which is consistent with strong memory for the familiar object, given greater orientation and attention to the novel object. Thus, AAV-mediated Snapin overexpression rescues the deficits in nonspatial learning and memory, which were associated with mutant hAPP Tg mice.

To test spatial learning and memory, we performed the MWM test in 8- to 9-month-old mutant hAPP mice and WT littermates injected with AAV-Snapin or AAV control. Mice were trained to 
A

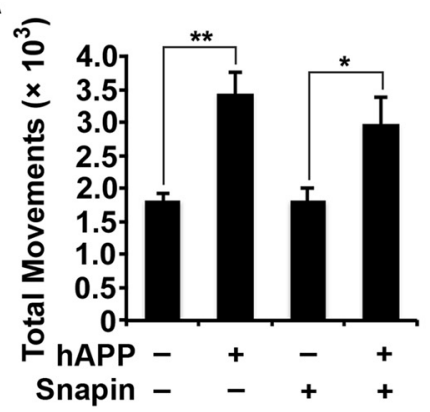

D

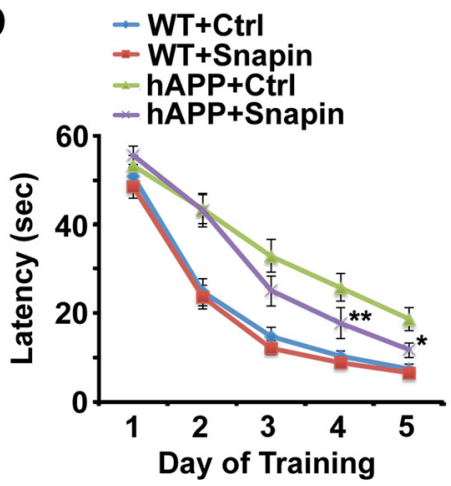

B

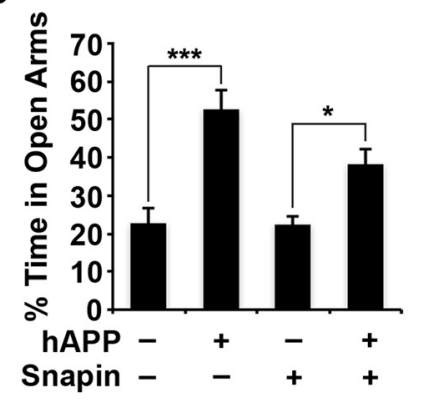

E

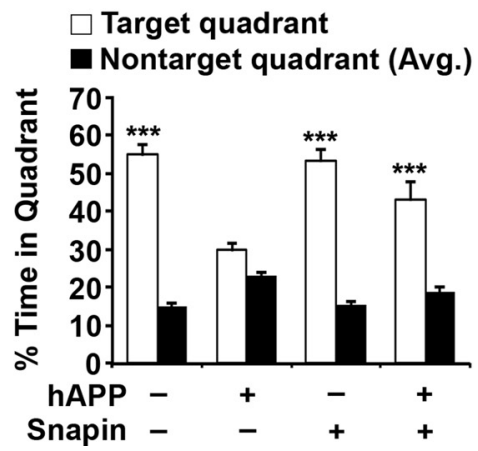

C

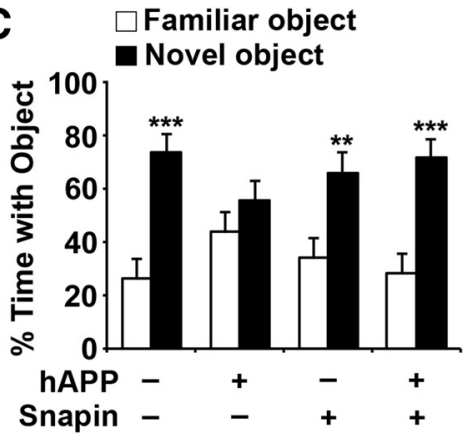

$\mathbf{F}$

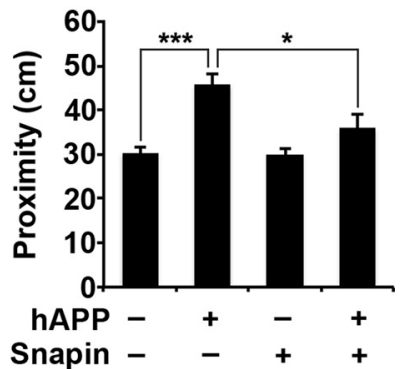

Figure 8. Elevated Snapin expression ameliorates deficits in spatial and nonspatial learning and memory in mutant hAPP Tg mice. $\boldsymbol{A}$-C, Effects of elevated Snapin levels were examined in open field, elevated plus maze, and novel object recognition tests ( $N=7-14$ male mice per genotype; 7-8 months of age). $A$, In the open field, hAPP mice were hyperactive compared to their WT littermates. The subtle difference in hyperactivity between hAPP mice with and without Snapin injection was not significant ( $p>0.05$; tw0-way ANOVA test). $\boldsymbol{B}$, In the elevated plus maze, hAPP mice spent more time in the open arms than their WT littermates. hAPP mice with increased Snapin expression showed no significant rescue effects on this phenotype ( $p=0.0791)$. Tw0-way ANOVA revealed a significant effect on hAPP $(p<0.0001)$ compared to WT mice. C, Mice were analyzed in the novel object recognition test. hAPP mice failed to spend more time with the novel than the familiar object in test session, which was reversed by elevated expression of Snapin. Two-way ANOVA of the average ratios of time spent with the novel versus the familiar object revealed a significant difference in hAPP mice injected with Snapin ( $p<0.0001$ by two-way ANOVA test), but not hAPP mice $(p>0.05)$, which were similar to WT mice with ( $p<0.0001)$ or without Snapin $(p=0.0011)$. $\boldsymbol{D}-\boldsymbol{F}$, Elevated Snapin expression in hAPP mice prevented deficits in spatial learning and memory ( $N=7-14$ male mice per genotype; $8-9$ months of age). WT and hAPP mice injected with AAV control or AAV-Snapin were trained in the Morris water maze for $5 \mathrm{~d}$. Time (latency) before reaching the platform was recorded. A probe trial (platform removed) was conducted $24 \mathrm{~h}$ after the last training. $\boldsymbol{D}$, hAPP mice showed longer latency (time to find hidden platform) than WT mice from day 2 to day 5 ( $p<0.0001$ ). Elevated Snapin levels resulted in improved task learning in hAPP mice $\left(F_{(3,219)}=26.37, p=0.0085\right.$ at day $4 ; F_{(3,168)}=14.26, p=0.0252$ at day 5 ; one-way ANOVA), but had no effect in WT mice at any given day of training. $\boldsymbol{E}, \boldsymbol{F}$, During the probe trial, hAPP mice injected with AAV-Snapin, but not AAV control, favored the target quadrant $(\boldsymbol{E})$ and showed a reduction in the average proximity to the target location $(\boldsymbol{F})$. Two-way ANOVA of these data revealed a significant effect of hAPP compared to WT mice $(\boldsymbol{E}, p<0.0001 ; \boldsymbol{F}, p<0.0001)$ and a rescue effect of elevated Snapin expression in $\mathrm{hAPP}$ mice $(\boldsymbol{E}, p=0.0149 ; \boldsymbol{F}, p=0.0143)$, but not in WT mice. Error bars represent SEM. ${ }^{*} p<0.05 ;{ }^{* *} p<0.01$; ${ }^{* * *} p<0.001$.

find a hidden platform daily for $5 \mathrm{~d}$, with each day involving four acquisition trials spread across two sessions; this was followed with memory testing in a $60 \mathrm{~s}$ probe trial. WT mice with or without Snapin expression displayed similar latency to find the platform during the training phase, favored the target quadrant, and showed an increase in average proximity to the target location in the probe trial (WT vs WT plus Snapin), indicating that elevated Snapin expression caused no adverse effects in learning and memory in WT mice. In contrast, hAPP mice performed poorly in both the acquisition phase and the memory probe tests. However, AAV-mediated Snapin overexpression significantly improved learning and enhanced memory retention in hAPP mice, as evidenced by a shorter latency during training $\left(F_{(3,219)}=\right.$ $26.37, p=0.0085$ at day $4 ; F_{(3,168)}=14.26, p=0.0252$ on day 5 by one-way ANOVA), greater favor toward the target quadrant $(p=$ $0.0149)$, and closer distance to the target location $(p=0.0143)$ relative to hAPP mice injected with AAV control (hAPP vs hAPP plus Snapin; Fig. $8 D-F$ ). Therefore, elevated Snapin expression in mutant hAPP Tg mice ameliorates deficits in both nonspatial and spatial learning and memory tests.

We next examined the effects of Snapin expression on contextual memory in mice at $10-11$ months of age by using a contex- tual fear conditioning task (Phillips and LeDoux, 1992). hAPP mice with or without AAV-Snapin injection showed no detectable difference from WT littermates on the training task before and immediately after the footshock (Fig. 9A,B). WT mice injected with AAV control or AAV-Snapin exhibited contextual learning, with $43.43 \%$ and $46.28 \%$ of the time spent "freezing" in the operant chamber in anticipation of the shock, respectively (Fig. 9C). However, hAPP mice showed defects in this task, spending only $13.99 \%$ of the time freezing. Surprisingly, hAPP mice expressing Snapin exhibited significant amelioration of the learning deficit $(p=0.0369)$ compared to hAPP mice and performed similarly to WT mice $(p=0.1359)$. Consistent with the beneficial effects on $\mathrm{A} \beta$ accumulation and synapse loss, Snapin-enhanced BACE1 retrograde transport attenuates $\mathrm{A} \beta$ mediated synaptic toxicity, and thus rescues cognitive impairments in hAPP Tg mice.

\section{Discussion}

The amount of pathogenic $A \beta$ peptide generated in the brain depends on the BACE1 levels and its $\beta$-secretase activity. In AD brains, BACE1 accumulates in dystrophic neurites - a unique phenotype thought to contribute to synaptic dysfunction and 
A

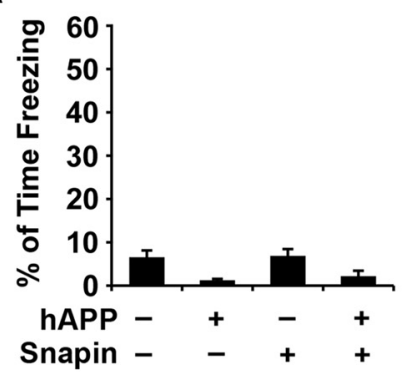

Habituation
B

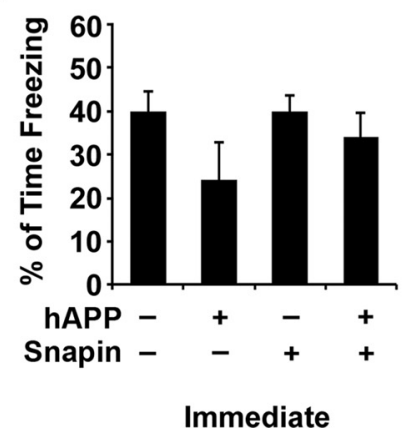

C

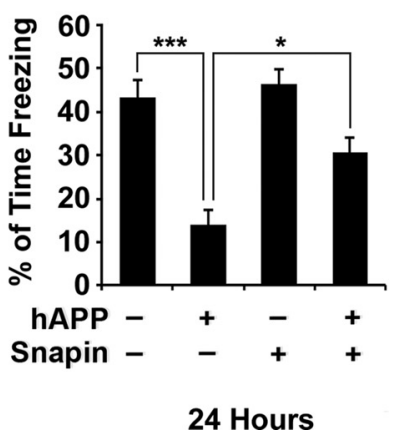

Figure 9. Elevated Snapin expression improves hippocampal-dependent learning in mutant hAPP Tg mice. A-C, Mutant hAPP Tg mice injected with AAV-Snapin exhibited improvement in a hippocampal-dependent contextual fear conditioning task ( $N=9-14$ male mice per genotype; $10-11$ months of age). All four groups showed similar levels of freezing before and immediately after the footshock $(\boldsymbol{A}, \boldsymbol{B})$. However, hAPP mice showed reduced levels of freezing at $24 \mathrm{~h}$ compared to WT littermates $(p<0.0001)$, which was attenuated by increasing Snapin expression $\left(p=0.0369\right.$ by two-way ANOVA test; $\boldsymbol{C}$. Error bars represent SEM. ${ }^{*} p<0.05 ;{ }^{* * *} p<0.001$.

axonal neurodegeneration by facilitating $A \beta$ overproduction (Buggia-Prévot and Thinakaran, 2015). Given the fact that intracellular trafficking and localization of BACE1 influences $\mathrm{A} \beta$ production, understanding the mechanisms regulating this pathway is crucial to dissecting how alterations in this pathway lead to synaptic BACE1 retention and enhanced $\beta$-secretase activity in AD brains. Although BACE1 has been reported to exhibit dynamic axonal transport, it remains unknown whether and how axonal transport regulates BACE1 trafficking and axonal distribution and consequently affects $\beta$ cleavage of APP at synaptic terminals. Investigation into these issues is an important emerging frontier in $\mathrm{AD}$ research that holds potential for clinical intervention.

Previous studies have provided important insights into BACE1 processing of APP in endosomes (Haass et al., 1992; Koo and Squazzo, 1994; Takahashi et al., 2002, 2004; He et al., 2005; Wu et al., 2011). We and others have shown that optimal $\beta$ secretase activity occurs in the acidic environments within LEs or multivesicular bodies, and that BACE1 is ultimately degraded in mature lysosomes located primarily in the soma (Huse et al., 2000; Koh et al., 2005; Tesco et al., 2007; Lefort et al., 2012; Ye and Cai, 2014). Our recent study demonstrated that BACE1 turnover largely depends on Snapin-mediated retrograde transport toward the soma (Ye and Cai, 2014). However, it remains unclear whether defective retrograde transport impairs BACE1 trafficking out of synapses and augments synaptic BACE1 cleavage of APP, thus contributing to $\mathrm{A} \beta$-mediated synaptotoxity in $\mathrm{AD}$ brains.

In the current study, we reveal that mutant hAPP Tg mice and AD patient brains exhibit aberrant accumulation of BACE1 within LEs enriched at presynaptic terminals (Figs. 1, 2). Defects in dynein-driven retrograde transport by genetic ablation of snapin in mice phenocopy late endocytic retention of BACE1 in distal axons and presynaptic terminals, and $\mathrm{A} \beta$ overproduction at the synapses (Figs. 3, 4). Moreover, we provide new evidence in live hAPP neurons that impaired retrograde transport leads to BACE1 retention within presynaptic LEs. Overexpression of Snapin facilitates BACE1-loaded LEs trafficking out of synapses by enhancing their retrograde transport and thus reduces presynaptic BACE1 accumulation (Fig. 5). More importantly, AAVmediated elevation of Snapin expression in the hippocampus of mutant hAPP Tg mouse brains decreases synaptic A $\beta$ levels, produces an ameliorative effect on the nonspatial and spatial memory impairments, and rescues the contextual memory deficits, which were associated with hAPP mice (Figs. 6-9). Therefore, Snapin-mediated BACE1 retrograde transport plays a critical role in the regulation of axonal trafficking and presynaptic localization of $\mathrm{BACE} 1$, thus modulating $\mathrm{A} \beta$ production at nerve terminals.

Although we did not detect any significant change in Snapin levels in the brains of mutant hAPP Tg mice and AD patients (Ye and Cai, 2014; Fig. 2), we found a robust reduction in the dyneinSnapin (motor-adaptor) coupling and impaired recruitment of dynein motors to LEs in AD neurons. These deficits lead to impeded BACE1 retrograde transport in mutant hAPP neurons (Ye and Cai, 2014). Our current study further demonstrates that such impaired retrograde transport retains LE-loaded BACE1 in distal axons and thus facilitates presynaptic $\mathrm{A} \beta$ generation. Moreover, Snapin-enhanced retrograde transport removes BACE1 from distal axons and reduces presynaptic $\mathrm{A} \beta$ levels and $\mathrm{A} \beta$-mediated synaptic toxicity in hAPP mouse brains. These observations allow us to propose an attractive model: an AD-linked mechanism impairs dynein-Snapin coupling and thus BACE1 retrograde transport from distal axons, which results in BACE1 retention and enhanced BACE1 processing of APP at presynaptic terminals in $\mathrm{AD}$ brains.

BACE1 is accumulated within dystrophic neurites surrounding brain senile plaques, which contributes to $\mathrm{AD}$ pathogenesis (Zhang et al., 2009; Kandalepas et al., 2013; Buggia-Prévot et al., 2014; Sadleir et al., 2016). Localization of BACE1 at axonal processes and presynaptic terminals occurs before plaque onset. During the emergence of surrounding extracellular plaques, BACE1 elevation and associated $\mathrm{A} \beta$ overproduction can be detected within axons and presynaptic terminals that undergo a continuing process of swelling and dystrophy (Zhang et al., 2009). These previous findings suggest that BACE1-involved axonal pathogenesis plays a key role in plaque formation. In the current study, we demonstrate that APP amyloidogenic machinery is enriched in presynaptic late endocytic organelles in $\mathrm{AD}$ brains. Our study reveals, for the first time, that impeded retrograde transport leads to abnormal accumulation of BACE1 at the presynaptic terminals of hAPP neurons (Figs. 1, 2, 5). More importantly, we show that the removal of BACE1 from axonal terminals by elevated Snapin expression in mouse brains before the onset of plaques reverses BACE1 retention in distal axons and reduces synaptic $A \beta$ production, thereby leading to the rescue effects on both extracellular amyloid deposition and cognitive deficits (Figs. 6-9).

Consistent with previous studies (Mucke et al., 2000; Nagahara et al., 2009, 2013), we found $\sim 25.5 \%$ reduction in the density of SYP-labeled presynaptic terminals in mutant hAPP J20 Tg 
mice. Such a reduction in specific brain regions correlates strongly with cognitive dysfunction in $\mathrm{AD}$ and is associated with major synaptic transmission deficits (Sze et al., 1997; Hsia et al., 1999), thus supporting their pathophysiological relevance. We demonstrated that hAPP J20 mice displayed defects in spatial and nonspatial learning and memory, which is consistent with studies from many other groups (Cheng et al., 2007; Meilandt et al., 2009; Harris et al., 2010; Cissé et al., 2011; Nagahara et al., 2013; Minami et al., 2014). Importantly, injection with AAV-Snapin in hAPP mouse brains produced beneficial effects on the impairments of nonspatial and spatial learning and the contextual memory (Figs. $8 C-F, 9 A-C$ ), which correlates with increased density of presynaptic terminals in these rescued mice (Fig. $6 E, F)$. Thus, our in vivo rescue study further indicates that elevated Snapin expression effectively ameliorates synapse loss, thereby attenuating cognitive deficits in $\mathrm{AD}$ mice.

Previous studies have demonstrated that synaptic pathology critically depends on intracellular $\mathrm{A} \beta$ concentration, but not plaque load, suggesting a plaque-independent $\mathrm{A} \beta$ toxicity in $\mathrm{AD}$ pathogenesis (Lue et al., 1999; Mucke et al., 2000; Tampellini et al., 2010, 2011; Takahashi et al., 2013). Decreased synaptic density correlates inversely with intracellular $\mathrm{A} \beta$ levels, but is independent of plaque, further indicating that neuronal toxicity is induced by accumulation of soluble $\mathrm{A} \beta$ (Mucke et al., 2000). In this study, we demonstrated that intracellular $\mathrm{A} \beta$ is highly enriched at the synaptic terminals of $\mathrm{AD}$ mouse brains (Figs. $1 A$, $7 A$ ), which likely augments $\mathrm{A} \beta$-induced synaptic toxicity. Such synaptic $A \beta$ accumulation is attributed to late endocytic retention of BACE1 within the presynaptic terminals of AD neurons (Fig. 1A). Elevated Snapin expression reduces such an accumulation of intracellular $\mathrm{A} \beta$, particularly synaptic $\mathrm{A} \beta$, by removing late endocytic BACE1 from distal axons and presynaptic terminals. Increased amyloid deposition is highly correlated with excessive $\mathrm{A} \beta$ release at synapses (Cumming et al., 2004; Luo and Yan, 2010; Dislich and Lichtenthaler, 2012). We detected reduced amyloid plaque formation in mutant hAPP mice injected AAVSnapin, consistent with the reduction in synaptic A $\beta$ levels (Fig. 7). Thus, our results support the emerging view: impaired BACE1 retrograde transport contributes to synaptic $A \beta$ accumulation and $\mathrm{AD}$-associated cognitive deficits.

Our results did not exclude the possibility that Snapin overexpression also enhances autophagy function. Purified AVs from $\mathrm{AD}$ mice are enriched with $\mathrm{A} \beta$ peptide and thus are likely a reservoir of intracellular A $\beta$ (Yu et al., 2005; Yang et al., 2011; Nixon, 2013). We reported previously that Snapin-mediated retrograde transport is critical for the clearance of autophagic cargoes within mature lysosomes mainly located in the soma of neurons (Cai et al., 2010; Cheng et al., 2015). Given the fact that (1) autophagosomes are predominantly generated in distal axons (Maday et al., 2012) and (2) retrograde transport of autophagosomes toward the soma is driven by LE-loaded dynein-Snapin complexes upon fusion of autophagosomes with LEs (Cheng et al., 2015), Snapinenhanced retrograde transport may coordinate the removal of both autophagic $\mathrm{A} \beta$ and LE-loaded BACE1 from distal axons for lysosomal proteolysis in the soma, and thus more effectively reduce intracellular $\mathrm{A} \beta$ levels in $\mathrm{AD}$ neurons.

A previous study showed that APP and BACE1 convergence and APP cleavage occur at presynaptic terminals, thus triggering amyloidogenesis (Das et al., 2013). Recently, the same group further visualized cellular APP-BACE1 interactions by using bimolecular fluorescence complementation (Das et al., 2016). They elegantly demonstrated that APP and BACE1 were cotransported in axons and interacted during this transit. Consistent with these findings, we showed previously the coexistence of APP and BACE1 in LEs immunoisolated from mouse brains (Ye and Cai, 2014). Our current study provides new lines of evidence that these LE-associated BACE1 is accumulated within the presynaptic terminal of $\mathrm{AD}$ neurons, thus augmenting APP processing in mutant hAPP mouse brains. Enhanced retrograde transport by overexpressing Snapin alleviates aberrant accumulation of BACE1 and reduces $A \beta$ levels at synaptic terminals, thus leading to a beneficial effect on synaptic pathology in $\mathrm{AD}$ brains. Altogether, our results suggest a new cellular model: Snapin-mediated and dynein-driven retrograde transport regulates axonal BACE1 distribution and synaptic $\beta$ secretase activity. Future therapeutic approaches enhancing this transport route may thus help to ameliorate $\mathrm{A} \beta$-linked synaptotoxicity in $\mathrm{AD}$ brains.

\section{References}

Banker GA, Cowan WM (1979) Further observations on hippocampal neurons in dispersed cell culture. J Comp Neurol 187:469-493. CrossRef Medline

Bhalla A, Vetanovetz CP, Morel E, Chamoun Z, Di Paolo G, Small SA (2012) The location and trafficking routes of the neuronal retromer and its role in amyloid precursor protein transport. Neurobiol Dis 47:126-134. CrossRef Medline

Braak H, Braak E (1991) Neuropathological stageing of Alzheimer-related changes. Acta Neuropathol 82:239-259. CrossRef Medline

Buggia-Prévot V, Thinakaran G (2015) Significance of transcytosis in Alzheimer's disease: BACE1 takes the scenic route to axons. Bioessays 37: 888-898. CrossRef Medline

Buggia-Prévot V, Fernandez CG, Riordan S, Vetrivel KS, Roseman J, Waters J, Bindokas VP, Vassar R, Thinakaran G (2014) Axonal BACE1 dynamics and targeting in hippocampal neurons: a role for Rab11 GTPase. Mol Neurodegener 9:1. CrossRef Medline

Cai H, Wang Y, McCarthy D, Wen H, Borchelt DR, Price DL, Wong PC (2001) BACE1 is the major beta-secretase for generation of Abeta peptides by neurons. Nat Neurosci 4:233-234. CrossRef Medline

Cai Q, Lu L, Tian JH, Zhu YB, Qiao H, Sheng ZH (2010) Snapin-regulated late endosomal transport is critical for efficient autophagy-lysosomal function in neurons. Neuron 68:73-86. CrossRef Medline

Cai Q, Zakaria HM, Simone A, Sheng ZH (2012) Spatial parkin translocation and degradation of damaged mitochondria via mitophagy in live cortical neurons. Curr Biol 22:545-552. CrossRef Medline

Campsall KD, Mazerolle CJ, De Repentingy Y, Kothary R, Wallace VA (2002) Characterization of transgene expression and Cre recombinase activity in a panel of Thy-1 promoter-Cre transgenic mice. Dev Dynam 224:135143. CrossRef

Cheng IH, Scearce-Levie K, Legleiter J, Palop JJ, Gerstein H, Bien-Ly N, Puoliväli J, Lesné S, Ashe KH, Muchowski PJ, Mucke L (2007) Accelerating amyloid-beta fibrillization reduces oligomer levels and functional deficits in Alzheimer disease mouse models. J Biol Chem 282:2381823828. CrossRef Medline

Cheng XT, Zhou B, Lin MY, Cai Q, Sheng ZH (2015) Axonal autophagosomes recruit dynein for retrograde transport through fusion with late endosomes. J Cell Biol 209:377-386. CrossRef Medline

Chin J, Palop JJ, Puoliväli J, Massaro C, Bien-Ly N, Gerstein H, Scearce-Levie K, Masliah E, Mucke L (2005) Fyn kinase induces synaptic and cognitive impairments in a transgenic mouse model of Alzheimer's disease. J Neurosci 25:9694-9703. CrossRef Medline

Cissé M, Sanchez PE, Kim DH, Ho K, Yu GQ, Mucke L (2011) Ablation of cellular prion protein does not ameliorate abnormal neural network activity or cognitive dysfunction in the J20 line of human amyloid precursor protein transgenic mice. J Neurosci 31:10427-10431. CrossRef Medline

Coleman PD, Yao PJ (2003) Synaptic slaughter in Alzheimer's disease. Neurobiol Aging 24:1023-1027. CrossRef Medline

Cumming JN, Iserloh U, Kennedy ME (2004) Design and development of BACE-1 inhibitors. Curr Opin Drug Discov Devel 7:536-556. Medline

Das U, Scott DA, Ganguly A, Koo EH, Tang Y, Roy S (2013) Activityinduced convergence of APP and BACE-1 in acidic microdomains via an endocytosis-dependent pathway. Neuron 79:447-460. CrossRef Medline Das U, Wang L, Ganguly A, Saikia JM, Wagner SL, Koo EH, Roy S (2016) 
Visualizing APP and BACE-1 approximation in neurons yields insight into the amyloidogenic pathway. Nat Neurosci 19:55-64. Medline

DiGiovanni J, Sun T, Sheng ZH (2012) Characterizing synaptic vesicle proteins using synaptosomal fractions and cultured hippocampal neurons. Curr Protoc Neurosci 2:2.7.1-22. Medline

Dislich B, Lichtenthaler SF (2012) The membrane-bound aspartyl protease BACE1: molecular and functional properties in Alzheimer's disease and beyond. Front Physiol 3:8. Medline

Franklin KB, Paxinos G (2001) The mouse brain in stereotaxic coordinates, Ed 2. San Diego: Academic.

Fukumoto H, Rosene DL, Moss MB, Raju S, Hyman BT, Irizarry MC (2004) Beta-secretase activity increases with aging in human, monkey, and mouse brain. Am J Pathol 164:719-725. CrossRef Medline

Goslin K, Asmussen H, Banker G (1998) Rat hippocampal neurons in low density. In: Culturing nerve cells, Ed 2 (Banker G, Goslin K, eds), pp 339-370. Cambridge, MA: MIT.

Griffiths G, Hoflack B, Simons K, Mellman I, Kornfeld S (1988) The mannose 6-phosphate receptor and the biogenesis of lysosomes. Cell 52:329341. CrossRef Medline

Haass C, Koo EH, Mellon A, Hung AY, Selkoe DJ (1992) Targeting of cellsurface beta-amyloid precursor protein to lysosomes: alternative processing into amyloid-bearing fragments. Nature 357:500-503. CrossRef Medline

Harris JA, Devidze N, Halabisky B, Lo I, Thwin MT, Yu GQ, Bredesen DE, Masliah E, Mucke L (2010) Many neuronal and behavioral impairments in transgenic mouse models of Alzheimer's disease are independent of caspase cleavage of the amyloid precursor protein. J Neurosci 30:372-381. CrossRef Medline

He X, Li F, Chang WP, Tang J (2005) GGA proteins mediate the recycling pathway of memapsin 2 (BACE). J Biol Chem 280:11696-11703. CrossRef Medline

Hsia AY, Masliah E, McConlogue L, Yu GQ, Tatsuno G, Hu K, Kholodenko D, Malenka RC, Nicoll RA, Mucke L (1999) Plaque-independent disruption of neural circuits in Alzheimer's disease mouse models. Proc Natl Acad Sci U S A 96:3228-3233. CrossRef Medline

Huse JT, Pijak DS, Leslie GJ, Lee VM, Doms RW (2000) Maturation and endosomal targeting of beta-site amyloid precursor protein-cleaving enzyme. The Alzheimer's disease beta-secretase. J Biol Chem 275:3372933737. CrossRef Medline

Jankowsky JL, Slunt HH, Gonzales V, Savonenko AV, Wen JC, Jenkins NA, Copeland NG, Younkin LH, Lester HA, Younkin SG, Borchelt DR (2005) Persistent amyloidosis following suppression of Abeta production in a transgenic model of Alzheimer disease. PLoS Med 2:e355. CrossRef Medline

Jimenez S, Baglietto-Vargas D, Caballero C, Moreno-Gonzalez I, Torres M, Sanchez-Varo R, Ruano D, Vizuete M, Gutierrez A, Vitorica J (2008) Inflammatory response in the hippocampus of PS1M146L/APP751SL mouse model of Alzheimer's disease: age-dependent switch in the microglial phenotype from alternative to classic. J Neurosci 28:11650-11661. CrossRef Medline

Jimenez S, Torres M, Vizuete M, Sanchez-Varo R, Sanchez-Mejias E, TrujilloEstrada L, Carmona-Cuenca I, Caballero C, Ruano D, Gutierrez A, Vitorica J (2011) Age-dependent accumulation of soluble amyloid beta (Abeta) oligomers reverses the neuroprotective effect of soluble amyloid precursor protein-alpha (sAPP(alpha)) by modulating phosphatidylinositol 3-kinase (PI3K)/Akt-GSK-3beta pathway in Alzheimer mouse model. J Biol Chem 286:18414-18425. CrossRef Medline

Kandalepas PC, Sadleir KR, Eimer WA, Zhao J, Nicholson DA, Vassar R (2013) The Alzheimer's beta-secretase BACE1 localizes to normal presynaptic terminals and to dystrophic presynaptic terminals surrounding amyloid plaques. Acta Neuropathol 126:329-352. CrossRef Medline

Kang EL, Biscaro B, Piazza F, Tesco G (2012) BACE1 protein endocytosis and trafficking are differentially regulated by ubiquitination at lysine 501 and the Di-leucine motif in the carboxyl terminus. J Biol Chem 287: 42867-42880. CrossRef Medline

Kang JS, Tian JH, Pan PY, Zald P, Li C, Deng C, Sheng ZH (2008) Docking of axonal mitochondria by syntaphilin controls their mobility and affects short-term facilitation. Cell 132:137-148. CrossRef Medline

Kayed R, Head E, Thompson JL, McIntire TM, Milton SC, Cotman CW, Glabe CG (2003) Common structure of soluble amyloid oligomers implies common mechanism of pathogenesis. Science 300:486-489. CrossRef Medline
Koh YH, von Arnim CA, Hyman BT, Tanzi RE, Tesco G (2005) BACE is degraded via the lysosomal pathway. J Biol Chem 280:32499-32504. CrossRef Medline

Koo EH, Squazzo SL (1994) Evidence that production and release of amyloid beta-protein involves the endocytic pathway. J Biol Chem 269: 17386-17389. Medline

Lazarov O, Lee M, Peterson DA, Sisodia SS (2002) Evidence that synaptically released beta-amyloid accumulates as extracellular deposits in the hippocampus of transgenic mice. J Neurosci 22:9785-9793. Medline

Leenders M, Gerwin C, Sheng ZH (2004) Multidisciplinary approaches for characterizing synaptic vesicle proteins. Curr Protoc Neurosci 2:2.7. Medline

Lefort R, Pozueta J, Shelanski M (2012) Cross-linking of cell surface amyloid precursor protein leads to increased beta-amyloid peptide production in hippocampal neurons: implications for Alzheimer's disease. J Neurosci 32:10674-10685. CrossRef Medline

Lue LF, Kuo YM, Roher AE, Brachova L, Shen Y, Sue L, Beach T, Kurth JH, Rydel RE, Rogers J (1999) Soluble amyloid beta peptide concentration as a predictor of synaptic change in Alzheimer's disease. Am J Pathol 155:853-862. CrossRef Medline

Luo X, Yan R (2010) Inhibition of BACE1 for therapeutic use in Alzheimer's disease. Int J Clin Exp Pathol 3:618-628. Medline

Maday S, Wallace KE, Holzbaur EL (2012) Autophagosomes initiate distally and mature during transport toward the cell soma in primary neurons. J Cell Biol 196:407-417. CrossRef Medline

Meilandt WJ, Cisse M, Ho K, Wu T, Esposito LA, Scearce-Levie K, Cheng IH, Yu GQ, Mucke L (2009) Neprilysin overexpression inhibits plaque formation but fails to reduce pathogenic $\mathrm{A} \beta$ oligomers and associated $\operatorname{cog}$ nitive deficits in human amyloid precursor protein transgenic mice. J Neurosci 29:1977-1986. CrossRef Medline

Miller KE, Sheetz MP (2004) Axonal mitochondrial transport and potential are correlated. J Cell Sci 117:2791-2804. CrossRef Medline

Minami SS, Min SW, Krabbe G, Wang C, Zhou Y, Asgarov R, Li Y, Martens LH, Elia LP, Ward ME, Mucke L, Farese RV Jr, Gan L (2014) Progranulin protects against amyloid beta deposition and toxicity in Alzheimer's disease mouse models. Nature medicine 20:1157-1164. CrossRef Medline

Mucke L, Selkoe DJ (2012) Neurotoxicity of amyloid beta-protein: synaptic and network dysfunction. Cold Spring Harb Perspect Med 2:a006338. Medline

Mucke L, Masliah E, Yu GQ, Mallory M, Rockenstein EM, Tatsuno G, Hu K, Kholodenko D, Johnson-Wood K, McConlogue L (2000) High-level neuronal expression of abeta 1-42 in wild-type human amyloid protein precursor transgenic mice: synaptotoxicity without plaque formation. J Neurosci 20:4050-4058. Medline

Nagahara AH, Merrill DA, Coppola G, Tsukada S, Schroeder BE, Shaked GM, Wang L, Blesch A, Kim A, Conner JM, Rockenstein E, Chao MV, Koo EH, Geschwind D, Masliah E, Chiba AA, Tuszynski MH (2009) Neuroprotective effects of brain-derived neurotrophic factor in rodent and primate models of Alzheimer's disease. Nat Med 15:331-337. CrossRef Medline

Nagahara AH, Mateling M, Kovacs I, Wang L, Eggert S, Rockenstein E, Koo EH, Masliah E, Tuszynski MH (2013) Early BDNF treatment ameliorates cell loss in the entorhinal cortex of APP transgenic mice. J Neurosci 33:15596-15602. CrossRef Medline

Nixon RA (2013) The role of autophagy in neurodegenerative disease. Nat Med 19:983-997. CrossRef Medline

Phillips RG, LeDoux JE (1992) Differential contribution of amygdala and hippocampus to cued and contextual fear conditioning. Behav Neurosci 106:274-285. CrossRef Medline

Roberson ED, Scearce-Levie K, Palop JJ, Yan F, Cheng IH, Wu T, Gerstein H, Yu GQ, Mucke L (2007) Reducing endogenous tau ameliorates amyloid beta-induced deficits in an Alzheimer's disease mouse model. Science 316:750-754. CrossRef Medline

Sadleir KR, Kandalepas PC, Buggia-Prévot V, Nicholson DA, Thinakaran G, Vassar R (2016) Presynaptic dystrophic neurites surrounding amyloid plaques are sites of microtubule disruption, BACE1 elevation, and increased A $\beta$ generation in Alzheimer's disease. Acta Neuropathol 132:235256. CrossRef Medline

Sannerud R, Declerck I, Peric A, Raemaekers T, Menendez G, Zhou L, Veerle B, Coen K, Munck S, De Strooper B, Schiavo G, Annaert W (2011) ADP ribosylation factor 6 (ARF6) controls amyloid precursor protein (APP) processing by mediating the endosomal sorting of BACE1. Proc Natl Acad Sci U S A 108:E559-E568. CrossRef Medline 
Shankar GM, Walsh DM (2009) Alzheimer's disease: synaptic dysfunction and Abeta. Mol Neurodegener 4:48. CrossRef Medline

Sheng JG, Price DL, Koliatsos VE (2002) Disruption of corticocortical connections ameliorates amyloid burden in terminal fields in a transgenic model of Abeta amyloidosis. J Neurosci 22:9794-9799. Medline

Sinha S, Anderson JP, Barbour R, Basi GS, Caccavello R, Davis D, Doan M, Dovey HF, Frigon N, Hong J, Jacobson-Croak K, Jewett N, Keim P, Knops J, Lieberburg I, Power M, Tan H, Tatsuno G, Tung J, Schenk D, et al (1999) Purification and cloning of amyloid precursor protein betasecretase from human brain. Nature 402:537-540. CrossRef Medline

Sze CI, Troncoso JC, Kawas C, Mouton P, Price DL, Martin LJ (1997) Loss of the presynaptic vesicle protein synaptophysin in hippocampus correlates with cognitive decline in Alzheimer disease. J Neuropathol Exp Neurol 56:933-944. CrossRef Medline

Takahashi RH, Milner TA, Li F, Nam EE, Edgar MA, Yamaguchi H, Beal MF, $\mathrm{Xu} \mathrm{H}$, Greengard P, Gouras GK (2002) Intraneuronal Alzheimer abeta42 accumulates in multivesicular bodies and is associated with synaptic pathology. Am J Pathol 161:1869-1879. CrossRef Medline

Takahashi RH, Almeida CG, Kearney PF, Yu F, Lin MT, Milner TA, Gouras GK (2004) Oligomerization of Alzheimer's beta-amyloid within processes and synapses of cultured neurons and brain. J Neurosci 24:35923599. CrossRef Medline

Takahashi RH, Capetillo-Zarate E, Lin MT, Milner TA, Gouras GK (2013) Accumulation of intraneuronal beta-amyloid 42 peptides is associated with early changes in microtubule-associated protein 2 in neurites and synapses. PLoS one 8:e51965. CrossRef Medline

Tampellini D, Capetillo-Zarate E, Dumont M, Huang Z, Yu F, Lin MT, Gouras GK (2010) Effects of synaptic modulation on beta-amyloid, synaptophysin, and memory performance in Alzheimer's disease transgenic mice. J Neurosci 30:14299-14304. CrossRef Medline

Tampellini D, Rahman N, Lin MT, Capetillo-Zarate E, Gouras GK (2011) Impaired beta-amyloid secretion in Alzheimer's disease pathogenesis. J Neurosci 31:15384-15390. CrossRef Medline

Tesco G, Koh YH, Kang EL, Cameron AN, Das S, Sena-Esteves M, Hiltunen M, Yang SH, Zhong Z, Shen Y, Simpkins JW, Tanzi RE (2007) Depletion of GGA3 stabilizes BACE and enhances beta-secretase activity. Neuron 54:721737. CrossRef Medline

Tian JH, Wu ZX, Unzicker M, Lu L, Cai Q, Li C, Schirra C, Matti U, Stevens D, Deng C, Rettig J, Sheng ZH (2005) The role of Snapin in neurosecretion: snapin knock-out mice exhibit impaired calciumdependent exocytosis of large dense-core vesicles in chromaffin cells. J Neurosci 25:10546-10555. CrossRef Medline

Vassar R, Bennett BD, Babu-Khan S, Kahn S, Mendiaz EA, Denis P, Teplow DB, Ross S, Amarante P, Loeloff R, Luo Y, Fisher S, Fuller J, Edenson S, Lile J, Jarosinski MA, Biere AL, Curran E, Burgess T, Louis JC, et al. (1999) Beta-secretase cleavage of Alzheimer's amyloid precursor protein by the transmembrane aspartic protease BACE. Science 286:735-741. CrossRef Medline

Vassar R, Kovacs DM, Yan R, Wong PC (2009) The beta-secretase enzyme BACE in health and Alzheimer's disease: regulation, cell biology, function, and therapeutic potential. J Neurosci 29:12787-12794. CrossRef Medline
Wu J, Petralia RS, Kurushima H, Patel H, Jung MY, Volk L, Chowdhury S, Shepherd JD, Dehoff M, Li Y, Kuhl D, Huganir RL, Price DL, Scannevin R, Troncoso JC, Wong PC, Worley PF (2011) Arc/Arg3.1 regulates an endosomal pathway essential for activity-dependent beta-amyloid generation. Cell 147:615-628. CrossRef Medline

Xiao Q, Yan P, Ma X, Liu H, Perez R, Zhu A, Gonzales E, Tripoli DL, Czerniewski L, Ballabio A, Cirrito JR, Diwan A, Lee JM (2015) Neuronaltargeted TFEB accelerates lysosomal degradation of APP, reducing A $\beta$ generation and amyloid plaque pathogenesis. J Neurosci 35:1213712151. CrossRef Medline

Xie Y, Zhou B, Lin MY, Wang S, Foust KD, Sheng ZH (2015) Endolysosomal deficits augment mitochondria pathology in spinal motor neurons of asymptomatic fALS mice. Neuron 87:355-370. CrossRef Medline

Yan R, Bienkowski MJ, Shuck ME, Miao H, Tory MC, Pauley AM, Brashier JR, Stratman NC, Mathews WR, Buhl AE, Carter DB, Tomasselli AG, Parodi LA, Heinrikson RL, Gurney ME (1999) Membrane-anchored aspartyl protease with Alzheimer's disease beta-secretase activity. Nature 402:533-537. CrossRef Medline

Yang DS, Stavrides P, Mohan PS, Kaushik S, Kumar A, Ohno M, Schmidt SD, Wesson D, Bandyopadhyay U, Jiang Y, Pawlik M, Peterhoff CM, Yang AJ, Wilson DA, St George-Hyslop P, Westaway D, Mathews PM, Levy E, Cuervo AM, Nixon RA (2011) Reversal of autophagy dysfunction in the TgCRND8 mouse model of Alzheimer's disease ameliorates amyloid pathologies and memory deficits. Brain 134:258-277. CrossRef Medline

Yang LB, Lindholm K, Yan R, Citron M, Xia W, Yang XL, Beach T, Sue L, Wong P, Price D, Li R, Shen Y (2003) Elevated beta-secretase expression and enzymatic activity detected in sporadic Alzheimer disease. Nat Med 9:3-4. CrossRef Medline

Ye X, Cai Q (2014) Snapin-mediated BACE1 retrograde transport is essential for its degradation in lysosomes and regulation of APP processing in neurons. Cell Rep 6:24-31. CrossRef Medline

Ye X, Sun X, Starovoytov V, Cai Q (2015) Parkin-mediated mitophagy in mutant hAPP neurons and Alzheimer's disease patient brains. Hum Mol Genet 24:2938-2951. CrossRef Medline

Yu WH, Cuervo AM, Kumar A, Peterhoff CM, Schmidt SD, Lee JH, Mohan PS, Mercken M, Farmery MR, Tjernberg LO, Jiang Y, Duff K, Uchiyama Y, Näslund J, Mathews PM, Cataldo AM, Nixon RA (2005) Macroautophagy-a novel Beta-amyloid peptide-generating pathway activated in Alzheimer's disease. J Cell Biol 171:87-98. CrossRef Medline

Zempel H, Thies E, Mandelkow E, Mandelkow EM (2010) Abeta oligomers cause localized $\mathrm{Ca}(2+)$ elevation, missorting of endogenous Tau into dendrites, Tau phosphorylation, and destruction of microtubules and spines. J Neurosci 30:11938-11950. CrossRef Medline

Zhang XM, Cai Y, Xiong K, Cai H, Luo XG, Feng JC, Clough RW, Struble RG, Patrylo PR, Yan XX (2009) Beta-secretase-1 elevation in transgenic mouse models of Alzheimer's disease is associated with synaptic/axonal pathology and amyloidogenesis: implications for neuritic plaque development. Eur J Neurosci 30:2271-2283. CrossRef Medline

Zhou B, Cai Q, Xie Y, Sheng ZH (2012) Snapin recruits dynein to BDNFTrkB signaling endosomes for retrograde axonal transport and is essential for dendrite growth of cortical neurons. Cell Rep 2:42-51. CrossRef Medline 